\title{
A study of transient variations in the Earth's electromagnetic field at equatorial electrojet latitudes in western Africa (Mali and the Ivory Coast)
}

\author{
J. Vassal ${ }^{1 *}$, M. Menvielle ${ }^{2 *}$, Y. Cohen ${ }^{3}$, M. Dukhan ${ }^{1}$, V. Doumouya ${ }^{4}$, K. Boka ${ }^{4}$, O. Fambitakoye ${ }^{5}$ \\ ${ }_{1}^{1}$ Laboratoire de Géophysique, ORSTOM, 72 route d'Aulnay, F-93140 Bondy, France \\ ${ }^{2}$ Equipe de Physique de la Terre et des Planètes (URA 1369), Bât. 504, Université Paris Sud, F-91405 Orsay cedex, France \\ ${ }^{3}$ Laboratoire de Géomagnétisme, IPGP, B89, 4 Place Jussieu, F-75252 Paris cedex 05, France \\ ${ }^{4}$ Laboratoire de Physique de l'Atmosphère, Université d'Abidjan, Abidjan, Cote D'Ivoire \\ ${ }^{5}$ Laboratoire de Géophysique, ORSTOM, 72 route d'Aulnay, F-93140 Bondy, France, now retired
}

Received: 20 February 1997 / Revised: 25 July 1997 / Accepted: 29 July 1997

\begin{abstract}
In the framework of the French-Ivorian participation to the IEEY, a network of 10 electromagnetic stations were installed at African longitudes. The aim of this experiment was twofold: firstly, to study the magnetic signature of the equatorial electrojet on the one hand, and secondly, to characterize the induced electric field variations on the other hand. The first results of the magnetic field investigations were presented by Doumouya and coworkers. Those of the electric field experiment will be discussed in this study. The electromagnetic experiment will be described. The analysis of the electromagnetic transient variations was conducted in accordance with the classical distinction between quiet and disturbed magnetic situations. A morphological analysis of the recordings is given, taking into consideration successively quiet and disturbed magnetic situations, with the results interpreted in terms of the characterization of external and internal sources. Particular attention was paid to the effects of the source characteristics on the induced field of internal origin, and to the bias they may consequently cause to the results of electromagnetic probing of the Earth; the source effect in electromagnetic induction studies. During quiet magnetic situations, our results demonstrated the existence of two different sources. One of these, the $S_{\mathrm{R}}^{\mathrm{E}}$ source, was responsible for most of the magnetic diurnal variation and corresponded to the well-known magnetic signature of the equatorial electrojet. The other source (the $\mathrm{S}_{\mathrm{R}}^{*} \mathrm{E}$ source) was responsible for most of the electric diurnal variation, and was also likely to be an ionospheric source. Electric and magnetic diurnal variations are therefore related to different ionospheric sources, and interpreting the electric diurnal variation as induced by the magnetic field diurnal variation is not relevant. Furthermore, the magnetotelluric probing of the upper mantle at dip equator latitudes with the electromagnetic diurnal variation is consequently im-
\end{abstract}

Correspondence to: $\mathrm{J}$. Vassal

* Present address: CETP/CNRS, 4 Avenue de Neptune, F-94107 Saint Maur Des Fosses Cedex, France possible to perform. In the case of irregular variations, the source effect related to the equatorial electrojet is also discussed. A Gaussian model of equatorial electrojet was considered, and apparent resistivities were computed for two models of stratified Earth corresponding to the average resistive structure of the two tectonic provinces crossed by the profile: a sedimentary basin and a cratonic shield. The apparent resistivity curves were found to depend significantly on both the model used and the distance to the center of the electrojet. These numerical results confirm the existence of a daytime source effect related to the equatorial electrojet. Furthermore, we show that the results account for the observed differences between daytime and night-time apparent resistivity curves. In particular, it was shown that electromagnetic probing of the Earth using the classical Cagniard-Tikhonov magnetotelluric method is impossible with daytime recordings made at dip latitude stations.

Key words. Electromagnetics (Transient and time domain) Geomagnetism and paleomagnetism (geomagnetic induction) Ionosphere (equatorial ionosphere)

\section{Introduction}

With the onset of continual monotoring of the Earth's electromagnetic field at different latitudes during the last century, it soon became apparent that some transient variations appeared each day while others occurred irregularly. In this way, it became possible to distinguish between quiet geomagnetic situations, when only the regular daily variations were present, and disturbed geomagnetic situations at other times. Such distinction were linked to the discrimination between two different physical processes; with the regular variations being related primarily to the atmospheric dynamo processes 
(see e.g., Mazaudier and Blanc, 1982; Kamide, 1988), and the irregular variations being mostly in response to energy inputs into the magnetosphere related to, for instance, magnetospheric storms and substorms (see e.g., Akasofu, 1977; Fairfield, 1990). This distinction is also relevant at dip equator latitudes, but both regular and irregular magnetic variations reflect the daytime singularity in ionospheric sources at these latitudes (Richmond, 1973). Following the definition of Chapman (1951), this singularity, and its magnetic signature during quiet situations are referred to as the equatorial electrojet.

Regular magnetic variations are related to ionospheric currents whose position and shape are roughly constant in a reference system fixed with respect to the Sun. The general name for this system is $S_{q}$, for solar quiet conditions. The same term is often used for naming either observed 'quiet' daily variations, or averages of them. Mayaud (1965a, b) proposed designating individual solar regular variation curves as $S_{R}$ curves in order to facilitate their study and describe their day-to-day variability. The $\mathrm{S}_{\mathrm{q}}$ variation is deduced from $S_{R}$ curves by averaging them over a given time interval, the result of which represents the most likely $S_{R}$ variation. We have adopted these definitions in the study that follows. However because of the particular behavior of the ionospheric sources of the regular variation at dip equator latitudes, the term, $S_{R}^{E}$, is hereinafter denoted as representing the individual solar regular variation curves at these latitudes, in accordance with Fambitakoye (1976).

The magnetic $S_{R}^{E}$ variation has been extensively studied for decades, and its behavior is now relatively well understood (see e.g., Forbes, 1981 for a review, and Doumouya et al., 1997). In contrast, the behavior of the electric field $\mathrm{S}_{\mathrm{R}}^{\mathrm{E}}$ has been matter of debate for decades. To our knowledge, two direct observations of electric field variations at dip equator latitudes were reported prior to the end of the 1980s, by Gish and Rooney (1930) in Huancayo (Peru), and by Hutton and Wright (1961) and Hutton (1962) in Ghana. These authors demonstrated the existence of a diurnal variation in electric fields at dip equator latitudes, and pointed out correlation between the observed electric field variations and the magnetic signature of the equatorial electrojet. These data were not used to investigate the question of induction in regions of dip equator latitudes. This question has since been addressed in a theoretical sense by many authors (see e.g., Srivastava, 1965; Hermance and Peltier, 1970; Peltier and Hermance, 1971; Schmucker, 1970), who derived impedance tensor estimates by introducing source field geometry into the magnetotelluric equations. However, the lack of simultaneous observations of both electric and magnetic field variations along a chain of equatorial stations has rendered impossible the validitation of theoretical results.

From November 1968 until March 1970, a magnetic experiment was carried out in Chad and in the Central African Republic. Six temporary magnetic stations linked to three permanent observatories made up a chain of nine recording points. The magnetic variations recorded during 171 quiet or almost-quiet days were digitized at the nine stations. An analysis of this unique magnetic data set resulted in an important contribution to the understanding of the temporal and spatial behavior of the equatorial electrojet (Fambitakoye, 1976; Fambitakoye and Mayaud, 1976a, b, c; Fambitakoye et al., 1976). In particular, the experiment provided quite clear experimental evidence that the internal part of the observed diurnal variation in the $S_{R}^{E}$ of the magnetic field is very weak, and practically negligible in the equatorial electrojet region (Fambitakoye and Mayaud, 1973; Fambitakoye et al., 1973).

These experimental results led Ducruix et al. (1977) to reconsider the question of induction by the $S_{R}^{\mathrm{E}}$ in the equatorial electrojet region. These authors described the induction by the $\mathrm{S}_{\mathrm{R}}^{\mathrm{E}}$ in terms of Earth rotation below ionospheric currents of fixed geometry and intensity. They showed that the induced electromagnetic field was nonexistant when the magnetic field had a zonal symmetry, and was therefore expected to be negligible, if nonexistent, around LT noon. On the contrary, it was likely to be significant at dawn and dusk, when nonzonal ionospheric currents coupled to the equatorial electrojet were present (Langel et al., 1993). More generally, the theoretical results established by Ducruix et al. (1977) clearly showed that an analysis of the daily electric field variation would provide information on the ionospheric current system coupled to the equatorial electrojet.

During the IUGG General Assembly held in 1987 in Vancouver (British Columbia, Canada), the Interdivisional Commission on Developing Countries proposed that IAGA run a program of coordinated intensive studies of the equatorial electrojet. This proposal resulted in the International equatorial electrojet Year (IEEY), during which intensive, coordinated, pluridisciplinary investigations were carried out in the equatorial electrojet region. A French committee for IEEY was established within the framework of the 'Comite National Français de Géophysique et de Géodésie', and planned the operating instrument networks in the African longitude sector during the 1992-1994 period.

A network of 10 electromagnetic stations were installed at African longitudes. The aim of this experiment was twofold: firstly, to study the magnetic signature of the equatorial electrojet, and compare the results to those established in Chad and the Central African Republic, and secondly, to characterize the induced electric field variations on the other hand. The first results of the magnetic field investigations were presented by Doumouya et al. (1997). Those of the electric field experiment will be discussed in this study.

The electromagnetic experiment is described in Sect. 2. Recordings of electromagnetic transient variations bear information about the primary inducing field on the one hand (i.e., the electromagnetic field of external origin), and on the secondary induced field on the other (i.e., the field induced in the crust and upper mantle). An analysis of these variations is conducted in this work in accordance with the classical distinction between quiet and disturbed magnetic situations. 
In Sect. 3 we provide a morphological analysis of the recordings, taking into consideration successively quiet and disturbed magnetic situations. Interpreting the results of the morphological analysis in terms of the characterization of external and internal sources requires some theoretical elaborations. As already stated, the morphological distinction between regular and irregular variations is linked to a discrimination between external sources characterized by different space and time constants, with the related induction processes being accordingly different (see e.g., Ducruix et al., 1977). We will therefore consider successively quiet and disturbed magnetic situations and, in each case, discuss the physical processes driving the induction prior to deriving results for ionospheric source behavior (Sect. 4).

Particular attention will also paid to the effects of the temporal and spatial characteristics of the external sources on the induced field of internal origin. Following the Cagniard-Tikhonov hypothesis (Tikhonov, 1950; Cagniard, 1953), magnetotelluric soundings are classically interpreted in terms of plane wave approximation, corresponding to conditions for which the penetration depth of the electromagnetic field in the conductive Earth (skin depth) is very small compared to the spatial wavelength of its external sources. If the plane wave approximation does not hold, the inductive response of the Earth depends on source geometry, corresponding to the source effect in electromagnetic induction studies. Neglecting this dependence may lead to a significant bias in the determination of the resistivity structure of the Earth. An analysis of the IEEY data presented in Sect. 4 provides, in particular, further confirmation of the existence of a significant source effect during daytime at dip equator latitudes, and makes clear that this effect can be accounted for in terms of induction by a gaussian distribution of east-west current at dip equator latitudes.

\section{The field experiment}

\subsection{The IEEY experiment in the African sector}

The primary objective of the IEEY was to study ionosphere dynamics in the equatorial region by means of pluridisciplinary investigations. The study was organized on a worldwide scale with three longitude sectors (Africa, America and Asia), with a coherent multidisciplinary program of experiments being conducted in each sector.

In the African sector, the ionosphere was probed by three ionosondes, one HF radar, and one interferometer. The ionosondes were installed at Dakar (Senegal), Ouagadougou (Burkina-Faso) and Korhogo (Ivory Coast), and operated in co-operation with the French CNET (Centre National d'Etude des Télécommunications). The HF radar was installed at Korhogo, and operated by the French CEA (Commissariat à l'Energie Atomique). The interferometer was installed at Korhogo, and driven by the British UCL (University College of London) group. In addition to these measurements, an electromagnetic experiment was conducted by a French group from ORSTOM (Institut Français de recherche scientifique pour le développement en coopération).

\subsection{The electromagnetic experiment}

During the year 1993, a magnetic land survey over repeat stations was performed in West Africa. The measurements taken enabled the determination of the regional mean field (undisturbed internal field), and subsequently that of the geographic position of the 1993.5 magnetic dip equator. At a longitude of $5^{\circ} \mathrm{W}$, the magnetic dip equator was located at $11.20^{\circ} \mathrm{N}$.

The electromagnetic network was installed and operated by the ORSTOM geophysical department along a $1200 \mathrm{~km}$ long N-S profile which ran more or less along the $5^{\circ} \mathrm{W}$ meridian, between Tombouctou in Mali and Abidjan in Ivory Coast. Ten temporary electromagnetic stations was thus operated at geomagnetic dipole latitudes between $6^{\circ} .9 \mathrm{~N}$ (Tombouctou, TOM) and $6^{\circ} .27 \mathrm{~S}$ (Lamto, LAM). The geographic coordinates of each station were determined with the GPS (Global Positioning System) satellite system providing a precision better than $100 \mathrm{~m}$ for horizontal coordinates and $10 \mathrm{~m}$ for altitudes. (see Table 1). Data from three permanent African magnetic observatories [Mbour (MBO), Bangui (BNG) and Tamanrasset (TAM)] were also integrated into the electromagnetic data base. Figure 1 shows the locations of the stations and where the instrumentation was installed.

Table 1. Name, code, geographic location (north latitudes, west longitudes, dip geomagnetic latitudes in decimal degrees) and altitude of the IEEY electromagnetic stations

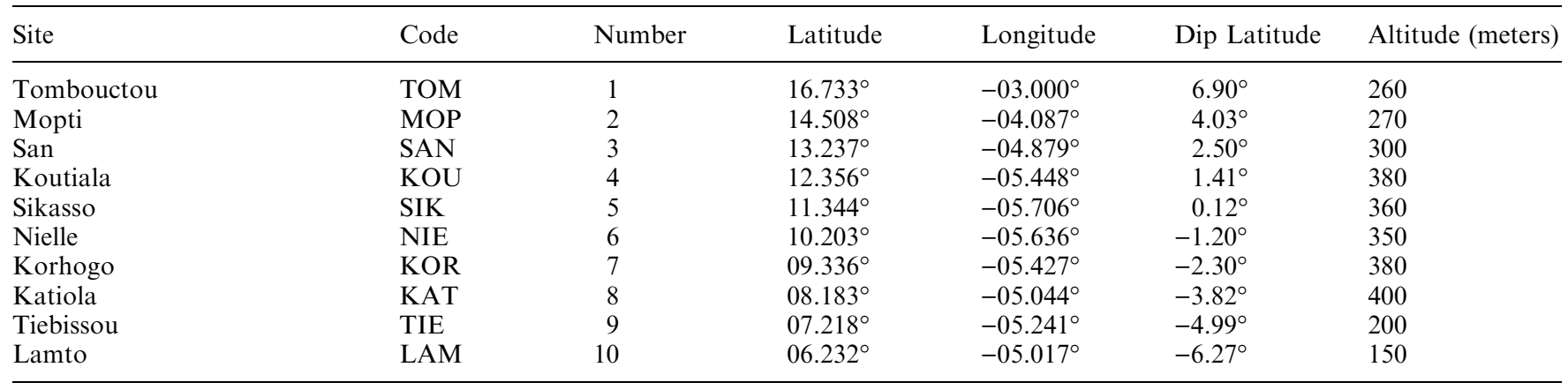




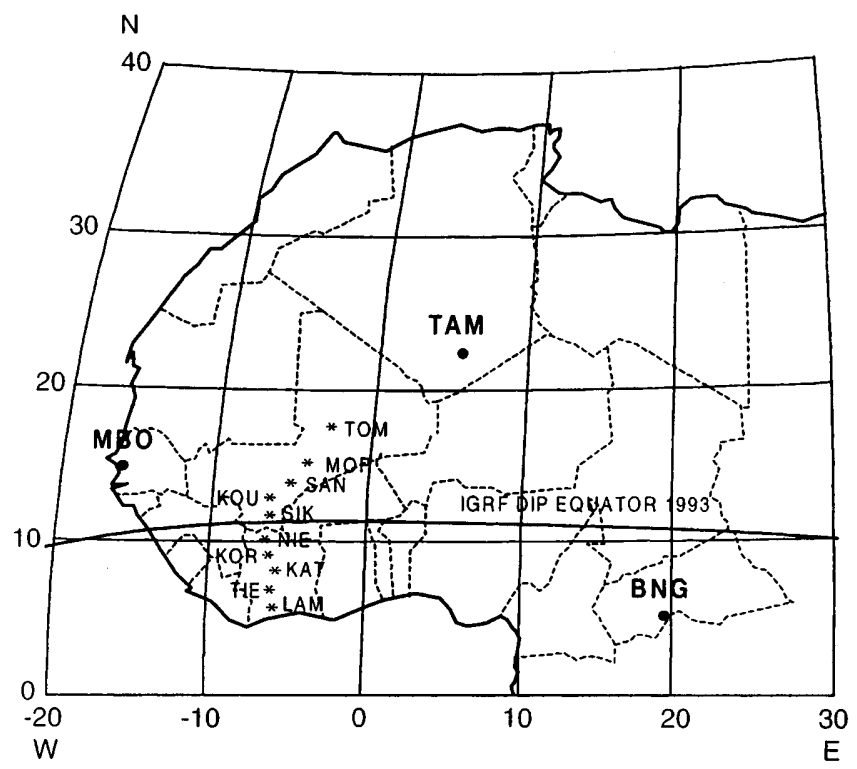

Fig. 1. The IEEY experiments in the African longitude sector. The geographic location of the stations of the IEEY electromagnetic profile $(*)$ and of the three permanent magnetic observatories $(O)$ used in this study: Mbour $(M B O)$, Bangui $(B N G)$ and Tamanrasset $(T A M)$. The $Z=0$ line corresponds to the 1993 IGRF dip equator

2.2.1 The instruments. Each electromagnetic field station consisted of Mosnier-type horizontal sensors and acquisition systems (Mosnier and Yvetot, 1972), which have already been used for several years to conduct magnetotelluric studies in west Africa (see e.g., Ritz and Vassal, 1986, 1987). The magnetic stations were modified for the specific purposes and needs of the IEEY project, and completed using a vertical magnetic sensor, the performance of which is similar to that of the horizontal Mosnier-type sensors.

2.2.1.1 The sensors. The horizontal magnetic sensors $\mathrm{H}$ $(\mathrm{N}-\mathrm{S})$ and $\mathrm{D}(\mathrm{E}-\mathrm{W})$ were classical Mosnier variometers, with a suspended magnet controlled by a capacitive system. They were used to measure the horizontal component of the transient field (Mosnier and Yvetot, 1977) and had an automatic compensation to maintain the analog output in the range of \pm 2 Volts, in addition to a sensitivity of $10 \mathrm{mV} / \mathrm{nT}$, an accuracy superior to $0.02 \mathrm{nT}$, and a thermal stability of about $0.02 \mathrm{nT} /{ }^{\circ} \mathrm{C}$. A vertical magnetic sensor designed by the EOPGS (Ecole et Institut de Physique du Globe, Strasbourg, France) and DT/INSU (Centre de Recherches Géophysiques, Garchy, France) teams was added for the IEEY experiment (Bitterly et al., 1988, Clerc, 1992). This sensor was a flux-gate magnetometer with a ThomsonSintra short linear probe $(\mathrm{L}=85 \mathrm{~mm}, \varnothing=18.5 \mathrm{~mm})$ and an analog output producing a direct current in the range of \pm 2 Volts with a sensitivity of $10 \mathrm{mV} / \mathrm{nT}$. The overall noise of the variometer was less than $0.1 \mathrm{nT} p-\mathrm{p}$ in the $0.2-2 \mathrm{~Hz}$ range. In order to minimize the thermal drift generated by diurnal and seasonal temperature variations, the magnetic sensors were buried underground at a depth of $1 \mathrm{~m}$.
Electric field variations were measured as potential differences between electrodes installed at the ends of two $200 \mathrm{~m}$ long lines oriented along N-S and E-W magnetic directions respectively. The measured potential differences resulted from the circulation of the geoelectric field between the two ends of the line, and were therefore proportional to the average value of the electric component along the line ( $E_{x}$ for the N-S line and $E_{y}$ for the E-W line, respectively). Each electrode was made from five thin sheets of lead metal $(20 \mathrm{~cm} \times 10 \mathrm{~cm})$ buried at a depth of $50 \mathrm{~cm}$. The measured electric signal was amplified, with the resultant output being in the range of $\pm 250 \mathrm{mV} / \mathrm{km}$ with a $0.13 \mathrm{mV} / \mathrm{km}$ sensitivity. In situ measurements showed that differential variations of temperature between two electrodes set $50 \mathrm{~cm}$ deep were about $0.2{ }^{\circ} \mathrm{C}$ for a daily temperature variation of about $15^{\circ} \mathrm{C}$ at the surface, thereby resulting in a negligible thermal drift of $5-10 \mu \mathrm{V}$.

Numerous types of electrodes are used in geophysical studies. The lead metallic electrodes employed here were not the most accurate available as their noise is significant $(100 \mu \mathrm{V}$ after $24 \mathrm{~h}$.) and they take a long time to stablilize (Petiau and Dupis, 1980). However, these electrodes are simple and strong. They may be locally manufactured from car lead batteries and have already been used at many occasions for electromagnetic sounding experiments in Africa. We were thus familiar with their behavior during harsh climatic conditions, and therefore used these electrodes because of their operational simplicity. During dry season (from November to April) the hydrologic characteristics of dry soil remained stable and, accordingly, the electrode polarization remained fairly constant. However, with the onset of the wet season, the polarization signal varied strongly and the quality of telluric signal became poor (on occasions it was out of recording range). Consequently, we did not record electric field variation during the wet season, which also limited the risk of destruction of the electronics at the station by lightning strikes.

2.2.1.2 Data acquisition. The numerical acquisition system was a Mosnier-type system developed by the CRG (Centre de Recherches Geophysiques, Garchy, France). The analogue outputs of various sensors were low-pass filtered with a $0.0083 \mathrm{~Hz}(120 \mathrm{~s})$ cut-off frequency using an analogue anti-aliasing filter with a $6 \mathrm{~dB} /$ octave slope. The signal was then digitized via a 12 bits A/D converter. The whole data acquisition procedure was controlled by a CPU allowing sampling intervals, in particular, to be selected. A one minute sampling interval was used during the IEEY experiment for measurement of both the telluric potential and magnetic signals. The data were then recorded as data blocks of 128 octets; each block comprised an 8-octet identification label followed by 120 octets of data. Each block thus corresponded to $12 \mathrm{~min}$ of 5-components of vector data. The data blocks were then stored sequentially on a RAM-type (Random Access Memory) memory card of 1 mega-octet providing a recording range of 66 days. 
In order to avoid problems related to difficult weather conditions, the electronic and data acquisition systems were installed in isothermal cases.

2.2.2 Field operations. The total power consumption of each station was about $5 \mathrm{~W}(12 \mathrm{~V}, 420 \mathrm{~mA})$. The instrumentation was powered by a sealed battery $(12 \mathrm{~V}, 45 \mathrm{Ah})$ charged by solar panels via a current regulator.

Each station was equipped with an ARGOS beacon that sent a 32 -octet message every $200 \mathrm{~s}$ providing the operational status of the station: battery charge level, date, hour, filling rate of the memory card, and 2 data per channel. This day-to-day monitoring of stations provided a quasi-real time monitoring of station status, allowing a rapid response to be initiated in case of technical problems. This equipment was installed in field conditions (i.e., buried in ground, for instance) over a two month period (April-May, 1992) in the vicinity of the Mbour magnetic observatory, and the magnetic field recordings at this location were compared with those of the observatory. The differences with the magnetic observatory recordings remained less than $\pm 1.5 \mathrm{nT}$.

Continuous recordings of the magnetic field were made at the IEEY electromagnetic stations between November 1992 and November 1994. During this period, the magnetic variations were continuously recorded, but recordings of the electric field variations were stopped during the rainy season as mentioned already. Electric field variations were thus recorded from November 1992 to April 1993 and from December 1993 to April 1994. Despite very difficult field conditions, the rate of station breakdown was fairly low, such that we were able to obtain continuous recordings over about $65 \%$ of the operation time.

A CD-ROM containing a technical description of the electromagnetic experiment and the IEEY data base (recorded minute values and computed hourly mean values) is available on request from ORSTOM, Bondy.

\section{The observed electromagnetic variations}

It is now well established that the Earth's magnetic field has a fairly simple behavior for the frequencies considered in this study [from about $10 \mathrm{cph}$ (cycle per hour) to $1 \mathrm{cpd}$ (cycle per day)] (see, e.g., Chapman, 1951; Fambitakoye and Mayaud, 1976a). In contrast, the behavior of transient variations in the electric field in equatorial regions was poorly understood before the present study.

Figure 2 shows magnetic field and electric field variations recorded in April 1993 at five stations evenly distributed along the longitudinal profile. The figure gives a striking illustration of the major finding of the IEEY electromagnetic experiment: that the overall behavior of the electric field is not as simple as that of the magnetic field. Furthermore, the relationship between transient variations in electric and magnetic fields actually has a quite complicated latitude and frequency

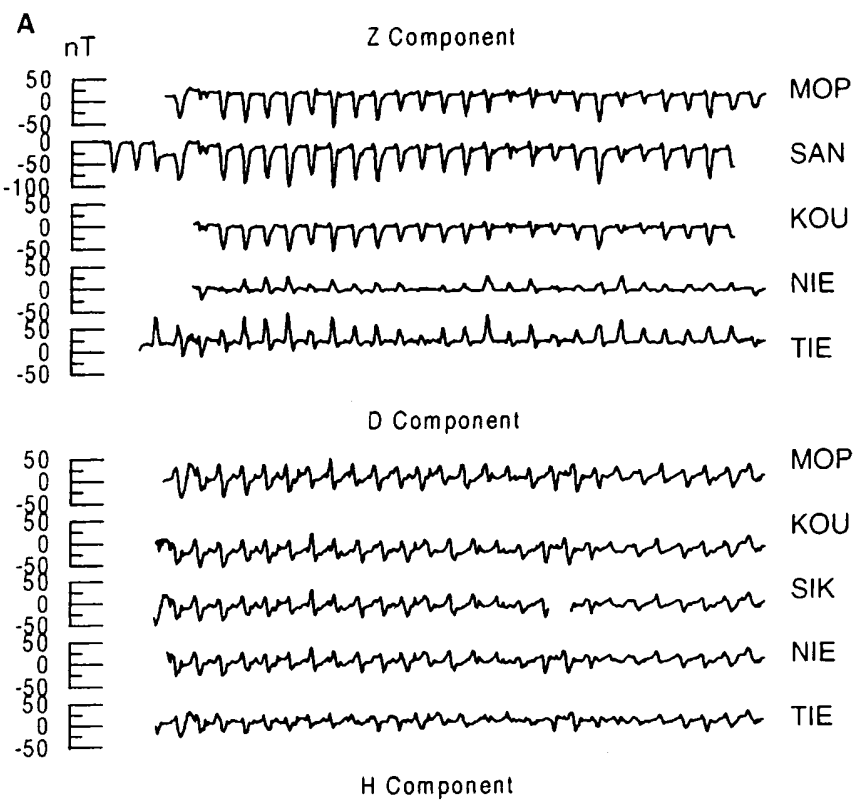

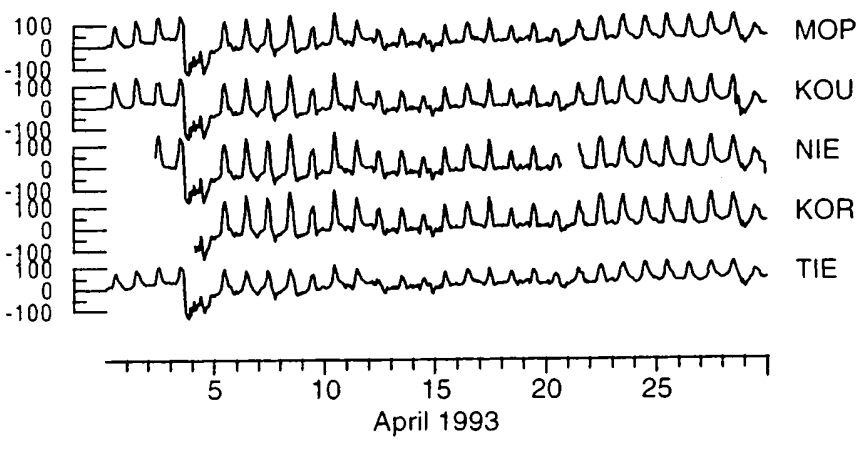

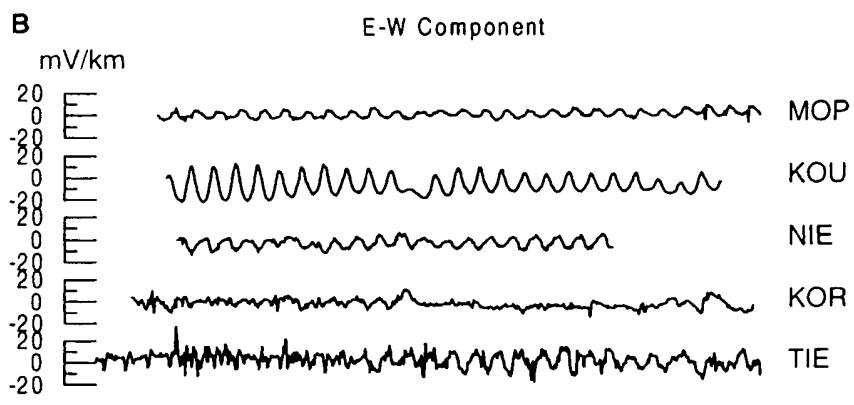

N-S Component

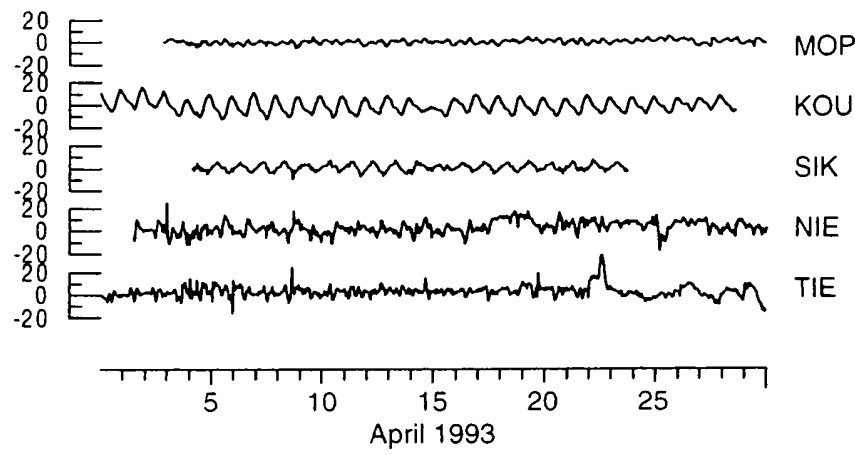

Fig. 2A, B. Transient variations of the electromagnetic field observed in April, 1993 at five stations of the electromagnetic profile. A Magnetic field; $\mathbf{B}$ electric field 
dependence. For instance, the electric field may dramatically change within relatively short distances. This is illustrated in Fig. 2B, where one can see that there are almost no common features between the electric field recordings made at the Koutiala (KOU) and Nielle (NIE) stations which were located $240 \mathrm{~km}$ apart. Furthermore, the observed latitude dependence of the electric field variations is not the same during magnetic quiet and disturbed situations.

We will therefore consider in turn the cases of quiet and disturbed magnetic situations. Because the Earth is conductive, the electromagnetic field at its surface is of both external and internal origin. For the sake of clarity, it is then worth first recalling the basic properties of the transient variations of the electromagnetic field at the surface of the conductive Earth.

\subsection{Primary and induced electromagnetic field}

The solid Earth is a conductive body in the midst of a time-varying magnetic field of external (ionospheric and magnetospheric) origin. Induction processes take place inside the conductive planet, and the electromagnetic field observed at the surface of the Earth is then the sum of the primary magnetic field of external origin, and of the induced electric and magnetic fields of internal origin.

When the horizontal space wavelength of the magnetic field is large enough for the plane wave approximation to be valid, the electromagnetic field can be described using the classical magnetotelluric equations (Tikhonov, 1950; Cagniard, 1953). When the electrical resistivity of the underlying medium depends only on depth, any horizontal component of the geoelectric field $\mathbf{E}$ is related in the frequency domain at any point on the surface of the medium to the perpendicular horizontal component of the geomagnetic field $\mathbf{H}$ through:

$\mathbf{E}(\omega) \cdot \mathbf{u}=Z(\omega) \mathbf{H}(\omega) \cdot \mathbf{v}$

where $\omega$ is the angular frequency of the electromagnetic field, and $Z(\omega)$ the complex inductive impedance of the underlying stratified medium; $\mathbf{u}$ and $\mathbf{v}$ are unit vectors in two horizontal perpendicular directions. In the presence of lateral contrasts of conductivity, the electromagnetic field is distorted and Eq. (1) is replaced by the classical tensorial magnetotelluric relation:

$\mathbf{E}(\omega)=Z(M, \omega) \mathbf{H}(\omega)$

where $Z(M, \omega)$ is the $2 \times 2$ complex impedance tensor of the underlying medium; $Z(M, \omega)$ depends on the observation point $M$.

When (1) the magnetotelluric approximation holds and (2) the distortion of the electromagnetic field remains quite small, a clear correlation exists between the transient variations of two crossed electric and magnetic horizontal components. This well-known morphological feature of the electromagnetic field may, however, be completely hidden in the presence of a strong distortion due to large conductivity contrasts in the vicinity of the recording station (see e.g., Menvielle,
1988 and references therein for a more complete analysis of the electromagnetic field distortion).

When the external sources have characteristic space wavelengths that are small enough such that the plane wave approximation is not valid, the space and time behavior of the induced electromagnetic field are driven by both the conductive structure of the Earth and the external source geometry. In particular, the impedance depends on the source geometry, resulting in source effects that could lead to significant errors when interpreting electromagnetic data if not properly taken into account. As will be seen later, this is the case during the daytime in equatorial regions because of the equatorial electrojet.

\subsection{Quiet magnetic situations}

The quiet magnetic situations correspond to quiet LT days selected using am indices (see e.g., Menvielle and Berthelier, 1991 for a review on am indices). The method used, described in the appendix, is similar to that proposed by Mayaud (1980) to determine the magnetic quietness of Greenwich UT days from $a a$ indices. There were about 30 quiet LT days during the 1992-1993 dry season. Figure 3 shows examples of magnetic field recordings (Fig. 3A) and electric field variations (Fig. 3B) during quiet periods.

3.2.1 Magnetic field variations. Figure 3A shows typical recordings of the $S_{\mathrm{R}}^{\mathrm{E}}$ magnetic curves at equatorial latitudes. The $H$ curves have the same typical morphology at all of the stations: the $\mathrm{S}_{\mathrm{R}}^{\mathrm{E}}$ regularly increased in the morning, between about 06:00 and 12:00 LT, reached its maximum around 12:00 LT then uniformly decreased down to the zero level by the evening, generally after 18:00 LT. For this component, the $S_{R}^{E}$ variations were positive at all the stations, and the intensity of their maximum value decreased with increasing distances from the dip equator. On some days, as it is the case on January 16, 1993 (Fig. 3A) for instance, a minimum value in the $\mathrm{H}$ variation is clearly visible at the Nielle (NIE), Sikasso (SIK) and Koutiala (KOU) stations prior to the beginning of the typical $\mathrm{S}_{\mathrm{R}}^{\mathrm{E}}$ variation. This minimum marks the presence of a morning counter electrojet (Gouin and Mayaud, 1967; Fambitakoye and Mayaud, 1976c) which was not clearly marked at the other stations because of the latitudinal asymmetry of the counter-electrojet with respect to the dip equator.

The morphology of the $\mathrm{S}_{\mathrm{R}}^{\mathrm{E}}$ curves for the $Z$ component was also typically the same at all the stations, but the signs change depending on the side of the dip equator: That is, they are positive to the south and negative to the north, and have, in both cases, their extremum around 12:00 LT. The $S_{\mathrm{R}}^{\mathrm{E}}$ variation was weak at those stations close to the dip equator. The counter electrojet of January 16 was clearly visible at all the stations, where a clear reversing variation could be seen prior to the beginning of the typical $\mathrm{S}_{\mathrm{R}}^{\mathrm{E}}$ variation. 
A

H

D

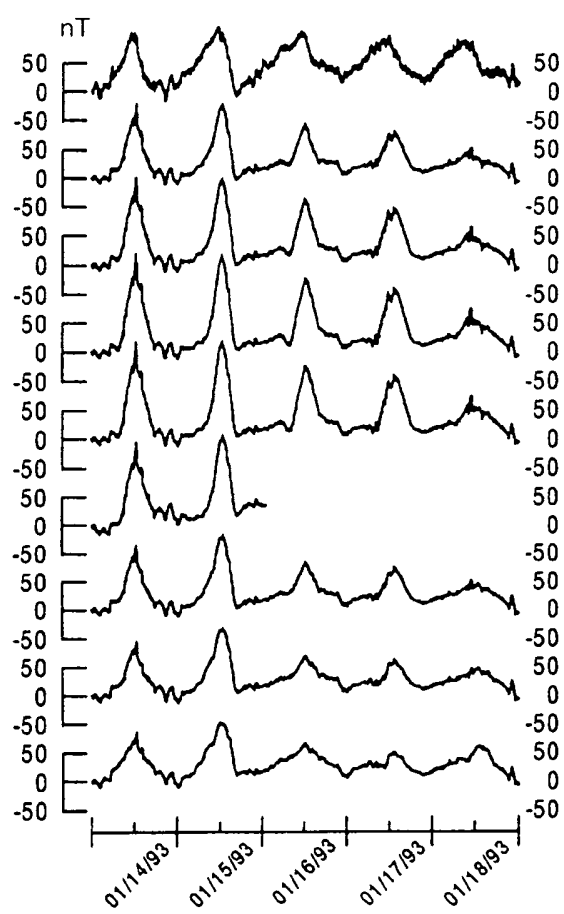

nT nT

Emrumarom ${ }_{-50}^{50} \mathrm{E}$

MOP

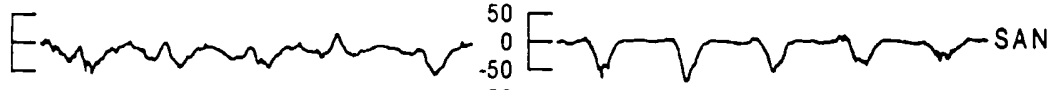

E

B

D
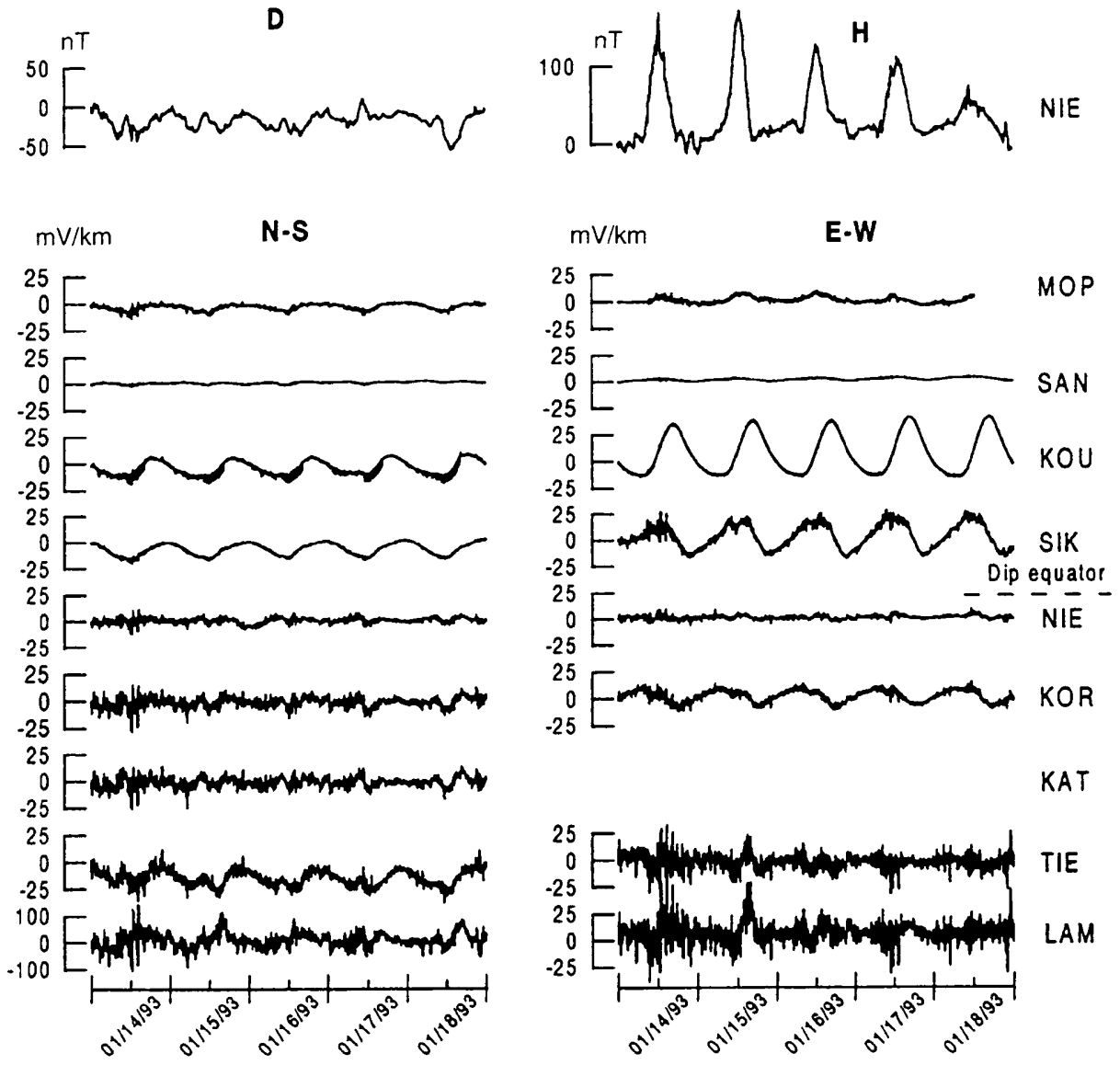

KAT

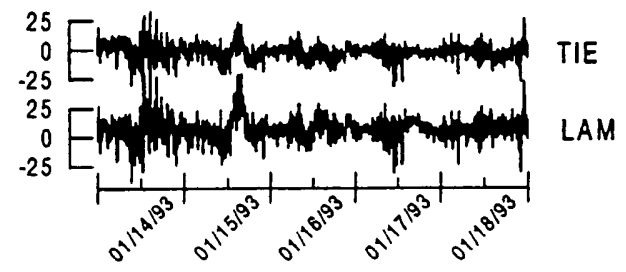

Fig 3A, B. Transient variations of the electromagnetic field observed during a 5 day long period of magnetic quietness with a significant magnetic day-to-day variability (January 14, 1993, 00:00 LT to January 18, 1993, 23:59 LT, with a maximum am value of $48 \mathrm{nT}$ and

an average am value of $23 \mathrm{nT}$ ). A magnetic field; $\mathbf{B}$ electric field, with the $D$ and $H$ magnetic component from the Nielle (NIE) station at the top of the left $\left(E_{x}\right)$ and right $\left(E_{y}\right)$ panels respectively 
Significant $\mathrm{S}_{\mathrm{R}}^{\mathrm{E}}$ variations were also observed for the $D$ component at all stations. For a given day, their morphology and amplitude did not vary significantly with latitude along the IEEY profile. Their intensity remained fairly small and, for this component, the dayto-day variability in the $S_{R}^{E}$ primarily resulted in significant changes to the morphology of the observed variations (see e.g., Doumouya et al., 1997 for a study of the day-to-day variability of the equatorial electrojet). It is beyond the scope of this study to discuss the link between the observed $\mathrm{S}_{\mathrm{R}}^{\mathrm{E}}$ variation for the $D$ component and those observed for the $H$ and $Z$ components.

3.2.2 Electric field variations. Figure 3B clearly shows that the observed electric field had a significant variation in $\mathrm{S}_{\mathrm{R}}^{\mathrm{E}}$ at most of the stations along the IEEY profile, as was expected from published observations already made at African longitudes. This figure also illustrates that, in contrast to what was expected from Cagniard-Tikhonov's magnetotelluric theory (see Sect. 3.1) and observed for the irregular variations and for the $S_{R}$ at midlatitudes (see e.g., Counil et al., 1984), there was actually no obvious correlation between the $S_{R}^{E}$ curves observed in two crossed components of the electric and magnetic fields $\left[E_{x}(\mathrm{~N}-\mathrm{S})\right.$ and $D$, or $E_{y}(\mathrm{E}-\mathrm{W})$ and $\left.H\right]$. The observed electric field $\mathrm{S}_{\mathrm{R}}^{\mathrm{E}}$ was thus very puzzling, and almost impossible to understand when observed at a single station, as already stated by Hutton and Wright (1961) and Hutton (1962).

At all of the stations, the $E_{x}$ and $E_{y} \mathrm{~S}_{\mathrm{R}}^{\mathrm{E}}$ curves crossed the zero level around 12:00 LT. They were positive in the morning and negative in the afternoon, or the opposite depending on the station and the component. Their extrema were observed at about 09:00 LT and 15:00 LT in any case of significant $S_{R}^{E}$ variation. Both the amplitude and morphology of the electric field $S_{R}^{E}$ curves varied significantly from one station to the other, and the latitude dependence on latitude was not the same for $E_{x}$ and $E_{y}$. For instance, the $\mathrm{S}_{\mathrm{R}}^{\mathrm{E}}$ curves were quite similar for $E_{x}$ at the Sikassou (SIK) and Koutiala (KOU) stations while significant changes in both amplitude and phase were observed between these two stations for $E_{y}$.

Figure 3B shows that the latitudinal dependence of the electric field $\mathrm{S}_{\mathrm{R}}^{\mathrm{E}}$ is characterized by significant changes within distances that may be less than $100 \mathrm{~km}$. In fact, the electric field $S_{\mathrm{R}}^{\mathrm{E}}$ variation reached its observed maximum at the Koutiala (KOU) station while it was almost zero at the San (SAN) station, located only $150 \mathrm{~km}$ to the north. Furthermore, the electric field $S_{R}^{E}$ variation was also almost zero at the Nielle (NIE) station, while at its maximum between this station and the San station. It was weak but visible at the Mopti (MOP), Korhogo (KOR) and Katiola (KAT) stations, and significantly increases to the south of the latter. The sharp increase in the $\mathrm{S}_{\mathrm{R}}^{\mathrm{E}}$ intensity observed at the Lamto (LAM) station corresponded to an effect of the nearby conductive ocean on the electric field. The electric field component along the direction perpendic- ular to the coast line was, in fact, enhanced in the resistive domain, as a result of conditions of continuity for the electric field. Small-scale variations with latitude were observed to the north of the dip equator during the boreal winter. Because of the lack of electric field recordings made during the austral winter, we do not know whether or not their location was dependent on the season.

Finally, Fig. 3B shows that the day-to-day variability of the electric field $S_{R}^{E}$ remained very small, even in the presence of an important day-to-day variability in the magnetic $S_{R}^{E}$.

3.2.3 Synthesis. As a result of their fairly simple latitude dependence and observed day-to-day variability, the observed $H$ and $Z$ components of the $\mathrm{S}_{\mathrm{R}}^{\mathrm{E}}$ curves were classically interpreted as the magnetic signature of an east-west ionospheric current the intensity of which was maximum at the dip equator and decreased with increasing distance from the dip equator. The time dependence of the observed $\mathrm{S}_{\mathrm{R}}^{\mathrm{E}}$ curves implied that the intensity of this current varied with LT, with a maximum occuring around 12:00 LT. At dip equator latitudes, most of the magnetic $S_{R}^{E}$ can then be accounted for as the magnetic signature of an east-west ribbon of ionospheric currents, whose intensity depended on both geomagnetic dipole latitude and local time.

Such a model does not satisfy the divergence-free condition for the ionospheric electric currents, and does not, therefore, account for the actual electromagnetic situation at dip equator latitudes. Closing ionospheric currents should actually exist. However, the results obtained using this simple model of the equatorial electrojet clearly show that the model provides a relevant first approximation, in particular around 12:00 LT where the equatorial electrojet has a zonal symmetry.

The electric $S_{R}^{E}$ does not have the same behavioral pattern as the magnetic $S_{R}^{E}$ :

a. The magnetic $H$ and $Z \mathrm{~S}_{\mathrm{R}}^{\mathrm{E}}$ curves are maximum (everywhere for $H$, and to the south of the dip equator for $Z$ ) or minimum (to the north of the dip equator for $Z$ ) around 12:00 LT. In contrast, the electric field $\mathrm{S}_{\mathrm{R}}^{\mathrm{E}}$ curves generally had morning and evening extrema (maximum then minimum, or the opposite depending on the station) and crossed the zero value at around 12:00 LT;

b. The day-to-day variability was a major feature of the magnetic $S_{R}^{E}$ while it was almost absent in the case of the electric field $S_{R}^{E}$;

c. The magnetic $S_{R}^{E}$ varied with latitude typically over a scale of few hundred kilometers, and was fairly well described by the IEEY electromagnetic network. On the contrary, the electric field $\mathrm{S}_{\mathrm{R}}^{\mathrm{E}}$ may vary significantly with latitude over distances that were small compared to the station spacing. Similar variations were not observed for the magnetic field recordings, resulting in this being the first report of such a phenomenon at equatorial latitudes. 


\subsection{The disturbed magnetic situations}

If disturbed magnetic situations are considered to be those LT days for which the am daily mean value was greater than $40 \mathrm{nT}$, then about 30 disturbed LT days took place during the 1992-1993 dry season. Over this period, continuous electric field recordings were made at the IEEY electromagnetic stations (see Appendix for a list of these days). Figure 4 shows an example of recordings of magnetic field and electric field variations during a very disturbed period (January 30, 21:00 LT to February 1, 12:00 LT), with an average am value of $72 \mathrm{nT}$.

\subsubsection{Magnetic field variations. Figure 4A clearly shows} that the irregular magnetic variations did not exhibit the same behavior at night as they did during the daytime. At night-time, the observed transient magnetic variations were almost homogeneous over the whole latitude range. The slight increase observed in the $Z$ variations to the south at the Lamto (LAM) station corresponded to the well-known coast effect (see e.g., Parkinson, 1959; Menvielle et al., 1982). The homogeneity of the magnetic variations observed at night corresponded to a lack of enhancement of ionospheric conductivity at the dip equator in the night hemisphere.

In contrast, observed daytime transient magnetic variations were dependent on latitude, with modulation of the intensity of $H$ variations occuring from north to south. Maximum variations were measured at the Nielle (NIE) station and decreased with increasing distance in northerly and southerly direction from this station. The direction of the $Z$ variations changed between the Nielle (NIE) and Koutiala (KOU) stations, below the center of the equatorial electrojet. To the north, their intensity increased between the Koutiala (KOU) and San (SAN) stations; to the south, the variations increased between the Nielle (NIE) and Katiola (KAT) stations, and then uniformly decreased with increasing distance from this station. The variations of the $D$ component were, in contrast, almost the same at all the stations.

3.3.2 Electric field variations. Figure 4B shows that, at all the IEEY stations, the observed $E_{x}$ and $E_{y}$ electric variations were, on average, significantly more intense during the day than at night, as a result of the daytime enhancement of the inducing magnetic variations related to the equatorial electrojet.

The $E_{x}$ variations were fairly well correlated with $D$ magnetic variations during both night and day. Their intensity, however, varied significantly with latitude: it was very small at the two stations located to the north of the dip equator [Mopti (MOP) and Koutiala (KOU)], while it was relatively large at those stations located to the south, with maximum between the stations of Korhogo (KOR) and Katiola (KAT). As was the case for the $\mathrm{S}_{\mathrm{R}}^{\mathrm{E}}$ variation, the sharp increase observed in the intensity of $E_{x}$ variations at the Lamto (LAM) station was related to the presence of the nearby conductive ocean.
Similarly, $E_{y}$ variations were well correlated with magnetic $H$ variations, with a significant dependence on latitude. They were small or even negligible, north of the Korhogo (KOR) station while they are significant south of this station.

The intensity of electric field variations thus increased by about one order of magnitude in going from north to south of the Korhogo (KOR) station. As this increase was observed during both night and day, it reflects changes in the conductive structure of the Earth. In contrast, a qualitative morphological analysis of the observed telluric potential variations did not identify whether or not the slight increase in the intensity observed during the day at the Korhogo (KOR) and Katiola (KAT) stations was present at night.

In order to achieve a more quantitative characterization of the behavior of the electric field at the IEEY stations, the root mean square $\tilde{E}$ of the observed electric variations over the time interval $\left[T_{0}\right.$ to $\left.\left(T_{0}+N \Delta t\right)\right]$ can be calculated, where $\Delta t$ is the one minute recording sampling rate:

$\tilde{E}=\frac{1}{N} \sqrt{\sum_{n=1}^{N}\left[E_{x}\left(T_{0}+n \Delta t\right)\right]^{2}+\left[E_{y}\left(T_{0}+n \Delta t\right)\right]^{2}}$

We considered night and day variations separately and computed the daily $\tilde{E}_{d}$ and $\tilde{E}_{n}$ values, corresponding to the 00-06 and 09-15 6-h LT intervals respectively, after high-pass filtering the electric field signal with a Butterworth filter with a cut-off frequency corresponding to $10800 \mathrm{~s}$. This allowed almost all regular variations in the signal to be filtered out, as illustrated in Fig. 5. This figure gives a striking illustration of the daytime enhancement of the intensity of the electric field, and of its latitude dependence for frequencies higher than $10^{-4} \mathrm{~Hz}$.

The $\tilde{E}_{d}$ and $\tilde{E}_{n}$ values for each station could therefore be used to characterize the mean intensity of the irregular magnetic variations for daytime and nighttime conditions, respectively. Using the Tiebissou (TIE) station as a reference station, we computed the daily values of the ratio $\tilde{E}_{d}(\mathrm{Sta}) / \tilde{E}_{d}(\mathrm{TIE})$ and $\tilde{E}_{n}(\mathrm{Sta}) /$ $\tilde{E}_{n}$ (TIE) for each station. On a daily basis, these ratios provided a quantitative estimate of the relative variation in the irregular variation intensity with latitude. Table 2 gives the expected values and variances of the set of ratios computed for daytime and night-time conditions at each station. At all the stations, with the exception of Sikasso (SIK) which was located close to the dip equator, the daytime and night-time ratios were not found to be statistically different, on account of the large standard deviations observed

3.3.3 Synthesis. The geometry of the daytime $H$ and $Z$ irregular variations corresponded to that of a magnetic field associated with an east-west ribbon of ionospheric currents. This is consistent with the very simple model of ionospheric conductivity deduced from the observed magnetic $S_{\mathrm{R}}^{\mathrm{E}}$ variation: the intensity of the ionospheric currents associated with the magnetic irregular varia- 
A

H

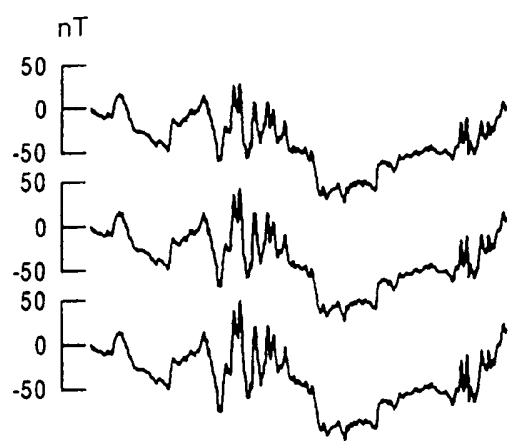

D

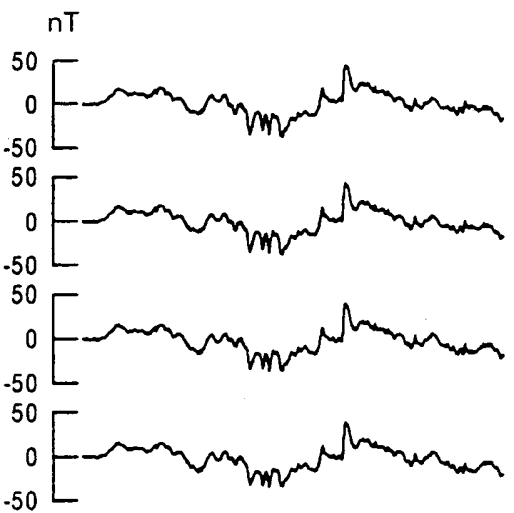

2

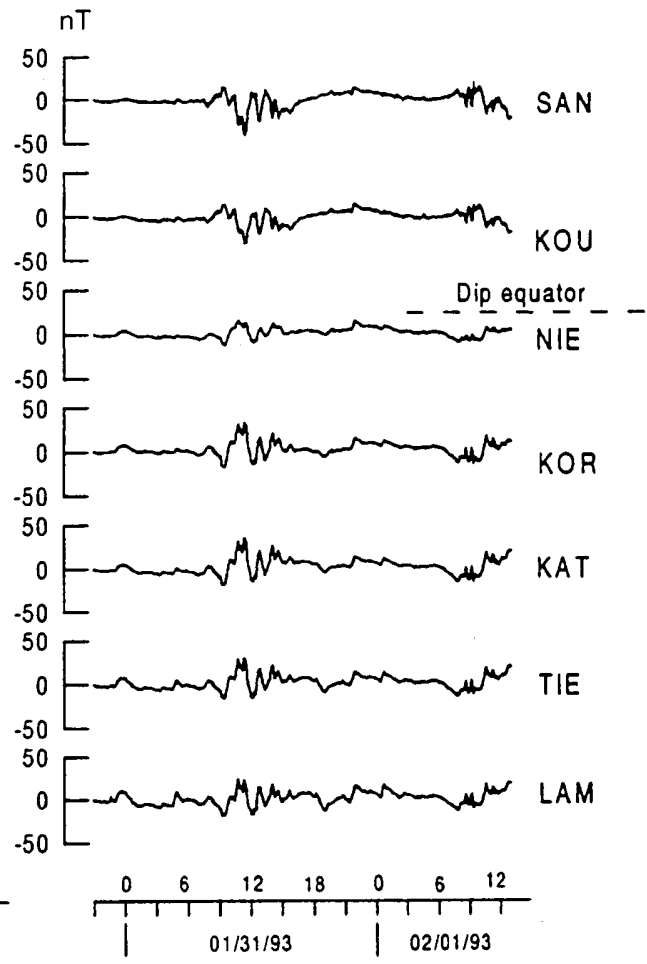

B

D
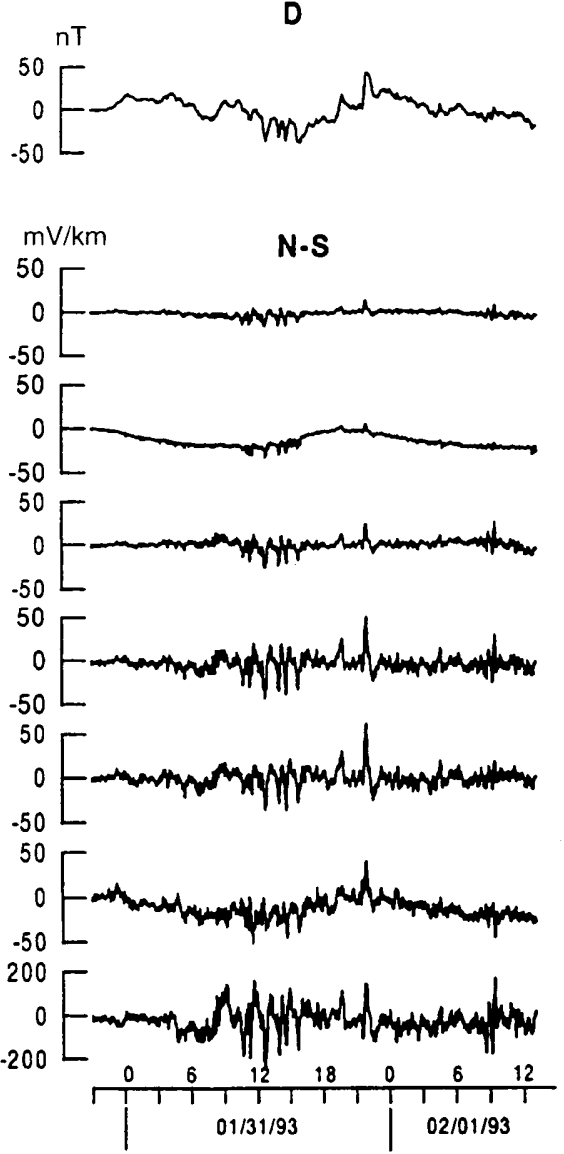
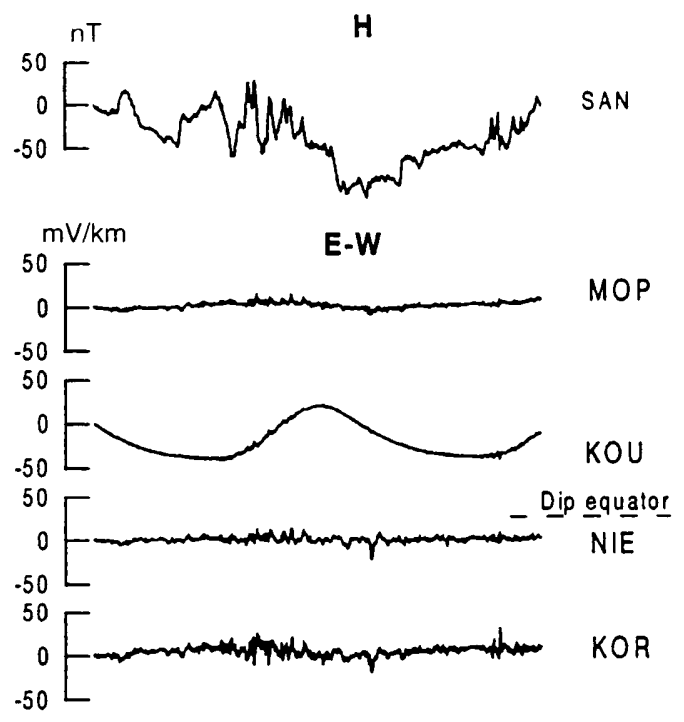

KAT

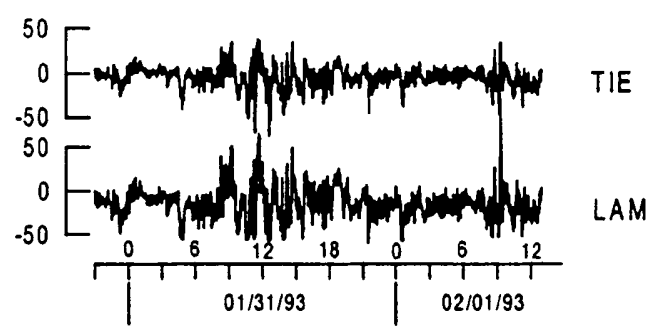

Fig. 4A, B. Transient variations of the magnetic field observed during a magnetic storm (January 31, 1993, 00:00 LT to February 1, 1993, 12:00 LT, with a maximum am value of $133 \mathrm{nT}$ and an average am value of $70 \mathrm{nT}$ ). A magnetic field; (B) electric field, with the $D$ and $H$ magnetic component from the San (SAN) station at the top of the left $\left(E_{x}\right)$ and right $\left(E_{y}\right)$ panels respectively 


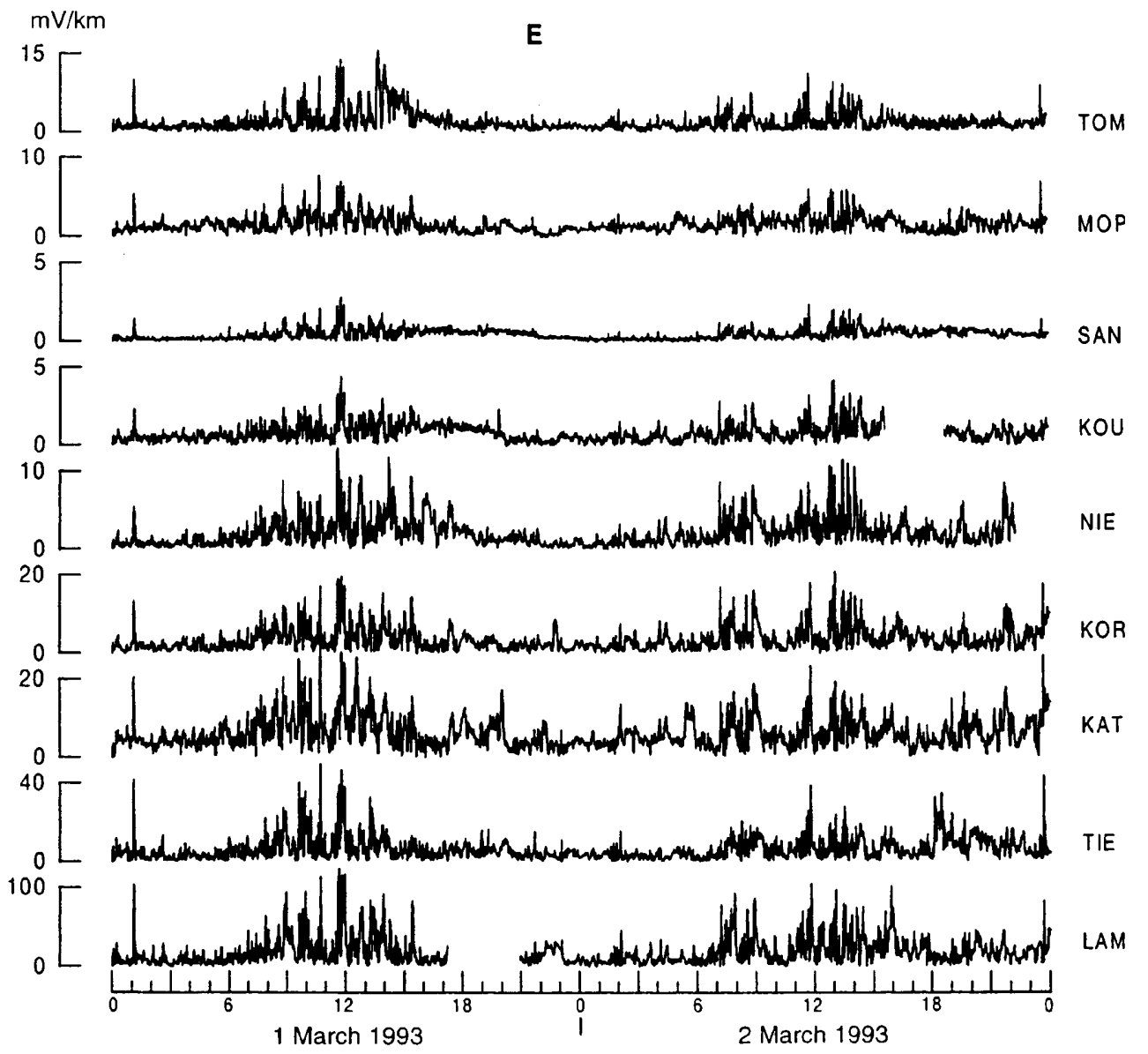

Fig. 5. Transient variations of the electric field modulus $E$ observed during a disturbed period (March 1, 1993, 00:00 LT to March 2, 1993, 23:59 $\mathrm{LT}$, with a maximum am value of $88 \mathrm{nT}$ and an average am value of $36 \mathrm{nT}$ )

tions increases in the vicinity of the magnetic equator as a result of the enhancement of ionospheric conductivity. However, the differences between the morphology of the observed $H$ and $Z$ variations (see e.g., between 06:00 and 09:00 LT, January 31), as well as the presence of irregular variations in the $D$ component have provided experimental evidences showing that this model does not account for the actual electromagnetic field behavior.

The observed electric variations clearly demonstrate a daytime enhancement of the intensity of the observed electric field variations, related to the daytime enhancement of ionospheric conductivity at dip equator lati-

Table 2. Values of the ratio $\mathbf{E}_{\mathrm{e}}$ (station)/ $\mathbf{E}_{\mathrm{e}}$ (TIE) for daytime and night-time intervals

\begin{tabular}{lll}
\hline Station & Day & Night \\
\hline TOM & $0.34 \pm 0.12$ & $0.28 \pm 0.05$ \\
MOP & $0.18 \pm 0.04$ & $0.19 \pm 0.02$ \\
SAN & $0.06 \pm 0.02$ & $0.05 \pm 0.01$ \\
KOU & $0.17 \pm 0.08$ & $0.13 \pm 0.07$ \\
SIK & $0.42 \pm 0.08$ & $0.29 \pm 0.06$ \\
NIE & $0.33 \pm 0.08$ & $0.32 \pm 0.10$ \\
KOR & $0.56 \pm 0.08$ & $0.59 \pm 0.15$ \\
KAT & $0.63 \pm 0.11$ & $0.70 \pm 0.20$ \\
TIE & Reference & Reference \\
LAM & $3.05 \pm 0.40$ & $3.16 \pm 0.68$ \\
\hline
\end{tabular}

tudes. Variations in the intensity of the irregular variations as a function of latitude were also observed along the IEEY profile. Because of the large observed standard deviations, no statistical difference between the day and night values for the ratio $\tilde{E}$ (Sta) $/ \tilde{E}$ (TIE) was observed. Consequently, such an integrative approach does not allow the effect of changes in the conductive structure of the Earth and those of the daytime source geometry to separated.

\section{Discussion}

It is clear from the morphological analysis made in Sect. 3 that the IEEY electromagnetic data provide the first comprehensive description of the behavior of both magnetic and electric field at equatorial latitudes for frequencies ranging from about $10 \mathrm{cph}$ to $1 \mathrm{cpd}$. The results presented in Sect. 3 demonstrate that these data bear information on both ionospheric sources and conductivity distribution in the Earth. In this section, we discuss the implications of these findings in terms of external and internal geophysics. Theoretical considerations will be necessary in order to conduct this discussion, which will consist initially of a review of relevant basic principles of induction theory. 
An understanding of the variations in the geomagnetic field at ground stations alone does not permit a 3dimensional distribution of these currents to be determined. Nevertheless, assuming a perfectly resistive atmosphere between the conductive Earth and the ionosphere, it is possible to account for the observations in terms of the gradient of a scalar harmonic potential. The upward continuation of this potential to the conductive shell of the ionosphere provides the geometry of the ionospheric equivalent currents. These currents are the only information that can be derived from ground-based stations alone, without further hypotheses being made. Conversely, any 3-dimensional distributions of ionospheric currents leading to the same system of ionospheric equivalent currents, and then to the same scalar potential in the resistive atmosphere gives rise to the same electromagnetic field at the surface of and inside the Earth. As we are only dealing with surface measurements, we will therefore model the equatorial electrojet as a thin sheet of currents located in the ionospheric E-layer.

\subsection{Theoretical considerations}

As mentioned in Sect. 3, the equatorial electrojet can be roughly modeled in the dayside hemisphere by a quasilinear concentration of currents flowing in the ionospheric E-layer along the dip equator. In order to ensure the divergence free condition for these currents, closing currents should exist, making it essential to deal with these currents when studying the induction phenomena associated with the equatorial electrojet. Although their geometry is poorly understood, it is worth considering that the geometry is not the same in the case of irregular variations or in the case of the $\mathrm{S}_{\mathrm{R}}^{\mathrm{E}}$ variation.

Let $\mathbf{B}_{\mathbf{e}}$ be the magnetic induction related to the external currents that flow in the electrojet, $\mathbf{B}_{\boldsymbol{i}}$ be the magnetic induction related to the induced currents that flow in the conducting solid Earth, and $\mathbf{B}$ be the total induction. $\mathbf{B}=\mathbf{B}_{\boldsymbol{i}}+\mathbf{B}_{\mathbf{e}}$ satisfies Maxwell's equation:

$$
\begin{aligned}
& \nabla \times \mathbf{B}=\mu \mathbf{J} \\
& \nabla \times \mathbf{E}=-\frac{\partial \mathbf{B}}{\partial t} \\
& \mathbf{J}=\sigma(\mathbf{E}+\mathbf{v} \times \mathbf{B}) \\
& \nabla \cdot \mathbf{B}=0 \\
& \nabla \cdot \mathbf{J}=0
\end{aligned}
$$

where $\mathbf{E}$ is the electric field, $\mathbf{J}$ the density of volume current, and $\mathbf{v}$ the linear speed of rotation of the Earth at the equator. $\sigma$ is the electrical conductivity of the medium, and $\mu$ its magnetic permeability, which we assume to be uniform and equal to that of a vacuum. The space is referred to an Oxyz Cartesian frame defined with respect to the Sun, where Ox and Oy are horizontal axes positive northwards and eastwards respectively, and $\mathrm{Oz}$ the vertical axis positive downwards.
Consider the case of homogeneous conductive domains. Taking the curl of Eq (4a) and substituting (4b) and $(4 \mathrm{c})$, gives:

$\nabla^{2} \mathbf{B}=\mu \sigma\left(\frac{\partial \mathbf{B}}{\partial t}-\nabla \times(\mathbf{v} \times \mathbf{B})\right)$

Similarly, taking the curl of Eq. (4b) and substituting (4a) and (4c) leads to:

$$
\nabla^{2} \mathbf{E}=\mu \sigma\left(\frac{\partial \mathbf{E}}{\partial t}-\frac{\partial}{\partial t}(\mathbf{v} \times \mathbf{B})\right)
$$

4.1.1 Induction by the $S_{R}^{E}$ variation. Ducruix et al. (1977) described the $S_{R}^{\mathrm{E}}$ ionospheric currents as a system of constant intensity and fixed geometry. In this limiting case, $\partial \mathbf{B} / \partial t$ and $\partial \mathbf{E} / \partial t$ are zero, and the Earth rotates below a current system that is fixed with respect to the Sun. The linear speed of rotation of the Earth, $\mathbf{v}$, lies along the y axis and:

$$
\nabla \times(\mathbf{v} \times \mathbf{B})=-v \partial \mathbf{B} / \partial y
$$

where $v=|\mathbf{v}|$. Consequently, the source term for the induction reduces to $\mu \sigma v \partial \mathbf{B} / \partial y$ in Eq. (5a) and (5b). Such a model results in the day-to-day variability of $\mathrm{S}_{\mathrm{R}}^{\mathrm{E}}$ being neglected. As the observed relative variation in the $\mathrm{S}_{\mathrm{R}}^{\mathrm{E}}$ between two consecutive days is generally smaller than $30 \%, \partial \mathbf{B} / \mathbf{B} \partial t$ is in the order of a few $10^{-6} \mathrm{~s}^{-1}$ while $v \partial \mathbf{B} / \mathbf{B} \partial y$ is around a few $10^{-5} \mathrm{~s}^{-1}$ during LT morning and afternoon hours. The day-to-day variability in $\mathrm{S}_{\mathrm{R}}^{\mathrm{E}}$ can therefore be neglected when studying the induction due to $\mathrm{S}_{\mathrm{R}}^{\mathrm{E}}$, except perhaps at times close to local noontime, such that the Ducruix et al. (1977) model provides a relevant first-order model of the $\mathrm{S}_{\mathrm{R}}^{\mathrm{E}}$ ionospheric currents.

In the case of currents fixed with respect to the Sun, Eq. (5a) and (5b) reduces to:

$$
\begin{aligned}
\nabla^{2} \mathbf{B} & =-\mu \sigma(\nabla \times(\mathbf{v} \times \mathbf{B})) \\
\nabla^{2} \mathbf{E} & =0
\end{aligned}
$$

Induced electric fields are therefore the signature of magnetic induction $\mathbf{B}$ gradients in the east-west direction. They are consequently expected to be negligible, if not zero, close to the noon meridian where $\partial \mathbf{B} / \partial y \approx 0$, and are likely to be the signature of closing currents which are, in fact, associated with $\mathbf{B}$ gradients in the $y$ direction. Furthermore, the differential operators present in Eq. (6b) Eq. (6a), (6b) only involve derivatives with respect to space. The magnetic induction, $\mathbf{B}$, and the induced electric field, $\mathbf{E}$, therefore have the same time dependence. Moreover, since $\mathbf{B}_{\boldsymbol{i}} \ll \mathbf{B}_{\mathbf{e}}$ (Ducruix et al., 1977), the ionospheric $\mathrm{S}_{\mathrm{R}}^{\mathrm{E}}$ currents together with the magnetic $S_{R}^{E}$ variation and the related induced electric $\mathrm{S}_{\mathrm{R}}^{\mathrm{E}}$ variation have the same time dependence during a given day. Their time variations are therefore proportional, such that a relative increase of $\alpha \%$ in the ionospheric current intensity would lead to a similar relative increase of $\alpha \%$ in the intensity of the observed magnetic and electric field variations. All of 
these variations would then have the same day-to-day variability.

A numerical illustration of this result can be found in Ducruix et al. (1977) who computed the induced electric fields for simple ionospheric current and Earth conductivity models. They considered both plane and spherical cases (Fig. 6A). Figure 6B shows the results they obtained for the spherical case, for which the source term becomes $(v / a) \partial \mathbf{B} / \partial \phi$, where $\phi$ is the latitude and $a$ the radius of the Earth. Furthermore, their results demonstrated that the intensity of the induced electric field was significant under the return flow of currents while it was almost zero at the noon meridian, where the external inducing field they considered had a zonal symmetry. On the other hand, their results showed that the intensity of the induced electric field was linearly related to that of the ionospheric currents, and therefore to that of the magnetic induction of external origin.

Although the models considered by Ducruix et al., (1977) are oversimplified, and probably not very realistic as far as the geometry of the ionospheric return currents is considered, they give a clear numerical confirmation of the two basic results we deduced from the Maxwell equation: that the induced electric fields correspond to the east-west gradient in the magnetic field, and that their intensity is proportional to that of the magnetic $S_{R}^{E}$ variation.

4.1.2 Induction by the irregular variations. During disturbed magnetic situations, the ionospheric currents flowing in the electrojet, and related to the irregular magnetic disturbances, are homogeneous over a wide range of longitudes and fluctuate temporally with time constants in the order of a few minutes to a few tens of minutes. The source term related to $\nabla \times(\mathbf{v} \times \mathbf{B})$ is then negligible compared to that related to $\partial \mathbf{B} / \partial t$, and, as a first approximation, one can consider that the current system does not move with respect to the Earth. Equations (5-a) and (5-b) then reduce to the classical induction equations for a conductive body in a timevarying electromagnetic field:

$$
\begin{aligned}
\nabla^{2} \mathbf{B} & =\mu \sigma \frac{\partial \mathbf{B}}{\partial t} \\
\nabla^{2} \mathbf{E} & =\mu \sigma \frac{\partial \mathbf{E}}{\partial t}
\end{aligned}
$$

Consider now the case of the induction at equatorial latitudes. At night time, the Tikhonov-Cagniard's plane wave approximation holds, and so does the magnetotelluric interpretation, briefly mentioned in Sect. 3.1. During daytime, however, the equatorial electrojet exercises considerable control over the transient electromagnetic field at the Earth's surface. Given the latitudinal extent of the equatorial electrojet (see this study, Sect. 3.3, and e.g., Fambitakoye and Mayaud, 1976a; Onwumechilli and Ozoemena, 1985; Doumouya et al., 1997), the plane wave approximation no longer holds for frequencies smaller than a few $\mathrm{cph}$, such that interpretation of daytime electromagnetic observations must take into account the actual distribution of ionospheric currents at equatorial latitudes.

The variation of the E-W current density with latitude has been studied for decades. Chapman (1951), followed by Fambitakoye and Mayaud (1976a) and Doumouya et al. (1997) modeled the equatorial electrojet as a 1-dimensional symmetrical distribution of E-W ionospheric currents scaled by its latitudinal extent and its intensity at the center:

$I(x)=I_{0}\left(1-\frac{x^{2}}{a_{p}^{2}}\right)^{m}$

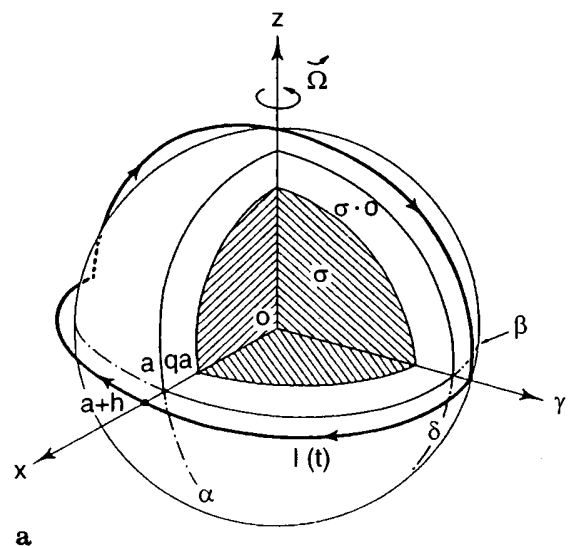

Fig. 6. A External current model and Earth conductivity Ducruix et al.'s (1977) model in the spherical case. Coordinate system Oxyz ( $\mathrm{r}, \mathrm{q}, \mathrm{f}$ ) is fixed with respect to the Earth. Current circuit (shown as a thick line, comprises a half equatorial circle and two half meridians on the sphere with radius $R=a+h$, where a is the Earth radius and $h$ the ionospheric altitude. The uniform conductive core has radius $q a$ and conductivity $s$. The current circuit rotates with velocity $\mathbf{W}=(2 \mathrm{p} /$ $\left.\mathrm{T}_{0}\right) \mathbf{z}$, with $T_{0}=24 \mathrm{~h}$. Parameters used by Ducruix et al. (1977) are

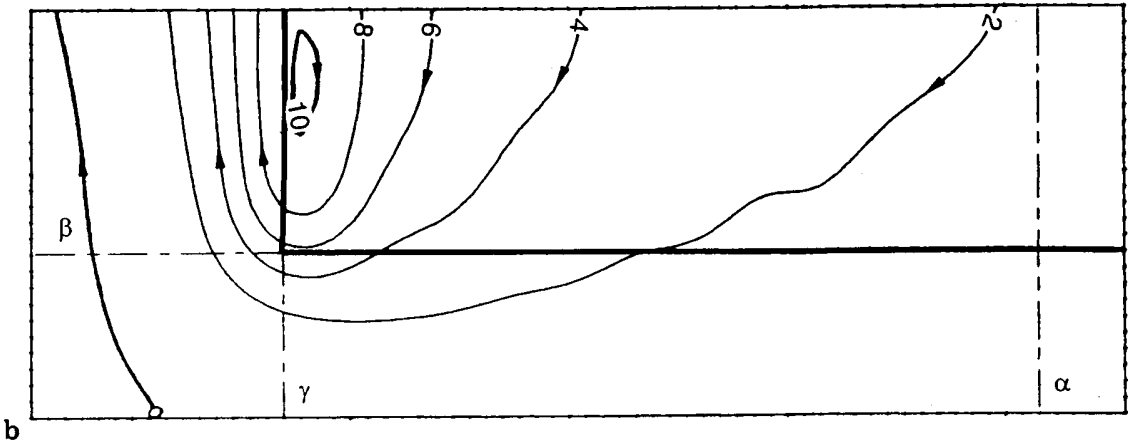

$a=6350 \mathrm{~km}, q a=5950 \mathrm{~km}, h=100 \mathrm{~km}$, and $s=10^{-2} \mathrm{~W}^{-1} \mathrm{~m}^{-1}$ (from Ducruix et al., 1977). B Map of the flow function at the conductive core surface. Ticks on the side of the frame indicate mesh spacing used by Ducruix et al. (1977) for numerical computation and are $2^{\circ}$ apart both in latitude and in longitude. The frame is bounded by $120^{\circ} \mathrm{W}$ to the left, $10^{\circ} \mathrm{E}$ to the right, $30^{\circ} \mathrm{N}$ to the top, and $20^{\circ} \mathrm{S}$ to the bottom. The current circuit is shown as a thick line. Units for the flow function are $\mathrm{Tm}^{2} \mathrm{~s}^{-1}$ (from Ducruix et al., 1977) 
where $I_{0}$ is the current density at the center of the electrojet, $a$ the 'half-width' of the electrojet and $x$ the distance to the center of the electrojet. Chapman (1951) considered uniform $(\mathrm{m}=0)$ and parabolic $(\mathrm{m}=1)$ distributions of current. Fambitakoye (1976) showed that quadratic models $(\mathrm{m}=2)$ account fairly accurately for the magnetic effects observed at the Earth's surface. Fambitakoye and Mayaud (1976a), and then Doumouya et al. (1997) used this latter model to characterize the day-to-day and seasonal variability of the equatorial electrojet and found that $a_{p}$ was of the order of $300 \mathrm{~km}$.

Surface magnetic data clearly shows that the equatorial electrojet ionospheric equivalent currents are symmetrical with respect to the center of the jet. Other symmetrical distributions of ionospheric equivalent currents have been used to solve the induction problem: For example, a cosine distribution with 'half-period' $a_{c}$ : (Hutton, 1972)

$\frac{I(x)}{I_{0}}=\cos \left(\frac{2 x}{a_{c}}\right)$

or a gaussian distribution scaled by a 'standard deviation' $a_{g}$ (Peltier and Hermance, 1971)

$\frac{I(x)}{I_{0}}=\exp \left(-\frac{x^{2}}{2 a_{g}^{2}}\right)$

Figure 7 shows that these three distributions do not differ significantly when they are close to the center of the electrojet, provided the $a_{p}, a_{c}$, and $a_{g}$ values are consistent. With a realistic $300 \mathrm{~km} a_{p}$ value and appropriate $a_{c}(320 \mathrm{~km})$ and $a_{g}(140 \mathrm{~km})$ values, the calculated error remains less than $10 \%$ for distances to the center

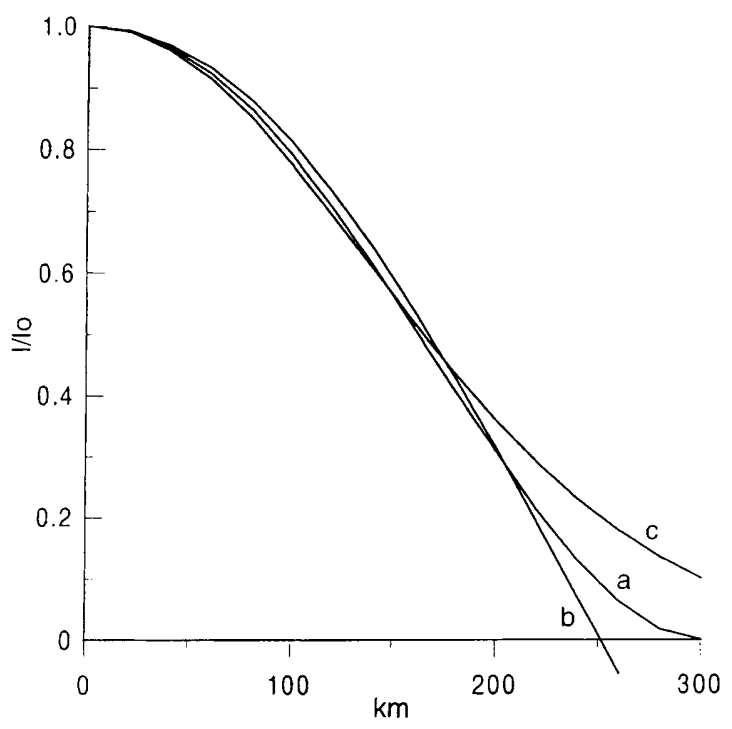

Fig. 7. Distribution of E-W ionospheric equivalent currents of the equatorial electrojet: $a$ Quadratic model with a $300 \mathrm{~km}$ half-width; $b$ cosine distribution with a $320 \mathrm{~km}$ half-period; $c$ gaussian distribution with a $140 \mathrm{~km}$ 'standard deviation' of the jet less than $250 \mathrm{~km}$. Nevertheless, the cosine model corresponds to ionospheric currents extending towards infinity in the N-S direction, and therefore does not account for the effects of the limited latitudinal extent of the equatorial electrojet. In contrast, the polynomial and gaussian models correspond to ionospheric currents of limited latitudinal extent, and are therfore likely to provide more realistic models of the electromagnetic field associated with the equatorial electrojet.

Peltier and Hermance (1971) solved the induction problem for gaussian distributions of currents. We used their results to compute the electromagnetic field for a realistic gaussian electrojet $\left(a_{g}=140 \mathrm{~km}\right)$ above a stratified conductive medium. Because the available geological information (Bessoles, 1977; Ponsard, 1984) made it clear that the southern stations (from Lamto to Nielle) were located on a resistive continental shield structure while the northern stations (from Koutiala to Mopti) were located on a conductive sedimentary basin, computations were made for two simplified models accounting for the average crust and upper mantle electric structure of these two major tectonic provinces. The models were deduced from already published results of regional magnetotelluric studies (see e.g., the synthesis made by Duhau and Favetto, 1990). They are described in Sect. 4.3 and Table 3.

The results obtained for frequencies ranging from $10^{-2}$ to $10^{-5} \mathrm{~Hz}(\sim 1 \mathrm{cpd})$ are presented in Table 4 and Fig. 8. As expected, the intensity of $H_{x}$ and $E_{y}$ do not have the same behavior. The intensity of $H_{x}$ decreased quite rapidly with increasing distances $x$ from the center of the electrojet, and the relative rate of decrease did not depend significantly on the model nor on the frequency. In contrast, the $E_{y}$ intensity depended on both the model and the frequency. For the high frequency range, the influence of the model was preponderant for both the intensity and relative variation of $E_{y}$. This was not the case for the low frequency range, in which $E_{y}$ decreased fairly slowly with increasing distances $x$, the relative rate of decrease depending significantly on the frequency and minimally on the model.

Table 3. Plane-layered models accounting for average crust and upper mantle electric structure of the two major tectonic provinces where the IEEY electromagnetic stations are located: a conductive sedimentary basin for the northern stations (from Koutiala to Mopti) and a continental shield structure for the south ern ones (from Lamto to Nielle). These models are used to evaluate the electromagnetic field and apparent resistivity curves presented in Table 4 and Figs. 8 and 9

\begin{tabular}{|c|c|c|c|}
\hline \multicolumn{2}{|l|}{$\begin{array}{l}\text { Model } 1 \\
\text { Craton }\end{array}$} & \multicolumn{2}{|l|}{$\begin{array}{l}\text { Model } 2 \\
\text { Basin }\end{array}$} \\
\hline $\begin{array}{l}\text { Resistivity } \\
\text { Ohm-m }\end{array}$ & $\begin{array}{l}\text { Depth } \\
\mathrm{km}\end{array}$ & $\begin{array}{l}\text { Resistivity } \\
\text { Ohm-m }\end{array}$ & $\begin{array}{l}\text { Depth } \\
\mathrm{km}\end{array}$ \\
\hline 10000 & 150 & 10 & 5 \\
\hline 1000 & 350 & 1000 & 150 \\
\hline 10 & - & 10 & - \\
\hline
\end{tabular}


Table 4. Values of the electric $\left(E_{0}\right)$ and magnetic $\left(H_{0}\right)$ components at $x=0$ for different periods and for the two models of earth described in Table 3

\begin{tabular}{|c|c|c|c|c|}
\hline \multirow[t]{2}{*}{ Ts. } & \multicolumn{2}{|c|}{ Model 1} & \multicolumn{2}{|c|}{ Model 2} \\
\hline & $E_{0}$ & $H_{0}$ & $E_{0}$ & $H_{0}$ \\
\hline 100 & $1.2 \mathrm{E}-3$ & $7.8 \mathrm{E}-2$ & $2.1 \mathrm{E}-4$ & 11. E-2 \\
\hline 500 & $3.1 \mathrm{E}-4$ & $7.1 \mathrm{E}-2$ & $9.8 \mathrm{E}-5$ & $9.7 \mathrm{E}-2$ \\
\hline 1000 & 1.7 E-4 & $6.9 \mathrm{E}-2$ & 7.2 E-5 & $8.2 \mathrm{E}-2$ \\
\hline 5000 & $4.0 \mathrm{E}-5$ & $6.6 \mathrm{E}-2$ & $2.7 \mathrm{E}-5$ & $7.5 \mathrm{E}-2$ \\
\hline 10000 & $2.1 \mathrm{E}-5$ & $6.6 \mathrm{E}-2$ & $1.5 \mathrm{E}-5$ & $7.3 \mathrm{E}-2$ \\
\hline 50000 & 4.6 E-6 & $6.4 \mathrm{E}-2$ & 3.8 E-6 & $6.8 \mathrm{E}-2$ \\
\hline 100000 & 2.4 E-6 & $6.4 \mathrm{E}-2$ & $2.1 \mathrm{E}-6$ & $6.6 \mathrm{E}-2$ \\
\hline
\end{tabular}

As was the case for the $\mathrm{S}_{\mathrm{R}}^{\mathrm{E}}$ variation, the 1-D models considered here were oversimplified because they did not take into account the actual 3-D geometry of the ionospheric closing currents. The results we obtained, however, showed that for frequencies lower than $10^{-3} \mathrm{~Hz}$ the electric field induced by the equatorial electrojet remained significant for distances up to $300 \mathrm{~km}$ from the center of the electrojet. This accounts for the significant increase in the intensity of the electric field variations observed during the daytime at the IEEY stations. Furthermore, the magnetic and electric fields did not have the same dependence on the distance to the center of the jet, and the equatorial electrojet accordingly gave rise to latitude dependent source effects in the magnetotelluric impedance.

\subsection{Inferences on the ionospheric sources}

For frequencies ranging from a few cph to a few cpd, most of the observed electric and magnetic transient variations can be accounted for in terms of an E-W ribbon of equivalent ionospheric currents symmetrical to, and roughly centered on, the dip equator. This simple model is actually a first-order approximation of the currents associated with the equatorial electrojet.

The approximation is not the same for the $\mathrm{S}_{\mathrm{R}}^{\mathrm{E}}$ variation. The spatial behavior of the observed electric $\mathrm{S}_{\mathrm{R}}^{\mathrm{E}}$ is not compatible with the geometry of the ionospheric currents classically associated with the magnetic $\mathrm{S}_{\mathrm{R}}^{\mathrm{E}}$. Furthermore, the difference between the observed electric and magnetic $\mathrm{S}_{\mathrm{R}}^{\mathrm{E}}$ day-to-day variability clearly indicates that the dominating parts in the observed electric and magnetic $S_{R}^{E}$ variations correspond to two different sources which are both likely to be ionospheric in nature. The magnetic signature of this second source should exist. The fact that it was not visible in the magnetic recordings indicates that it was very small compared to the magnetic signature of the equatorial electrojet, and actually hidden.

The observations made at the electromagnetic IEEY stations therefore demonstrate the existence of two different sources at equatorial latitudes:

1. The current systems associated with the equatorial electrojet that were responsible for the electric and magnetic variations in the higher frequency range (a few cph to a few cpd) and for most of the magnetic $S_{R}^{E}$ variation;
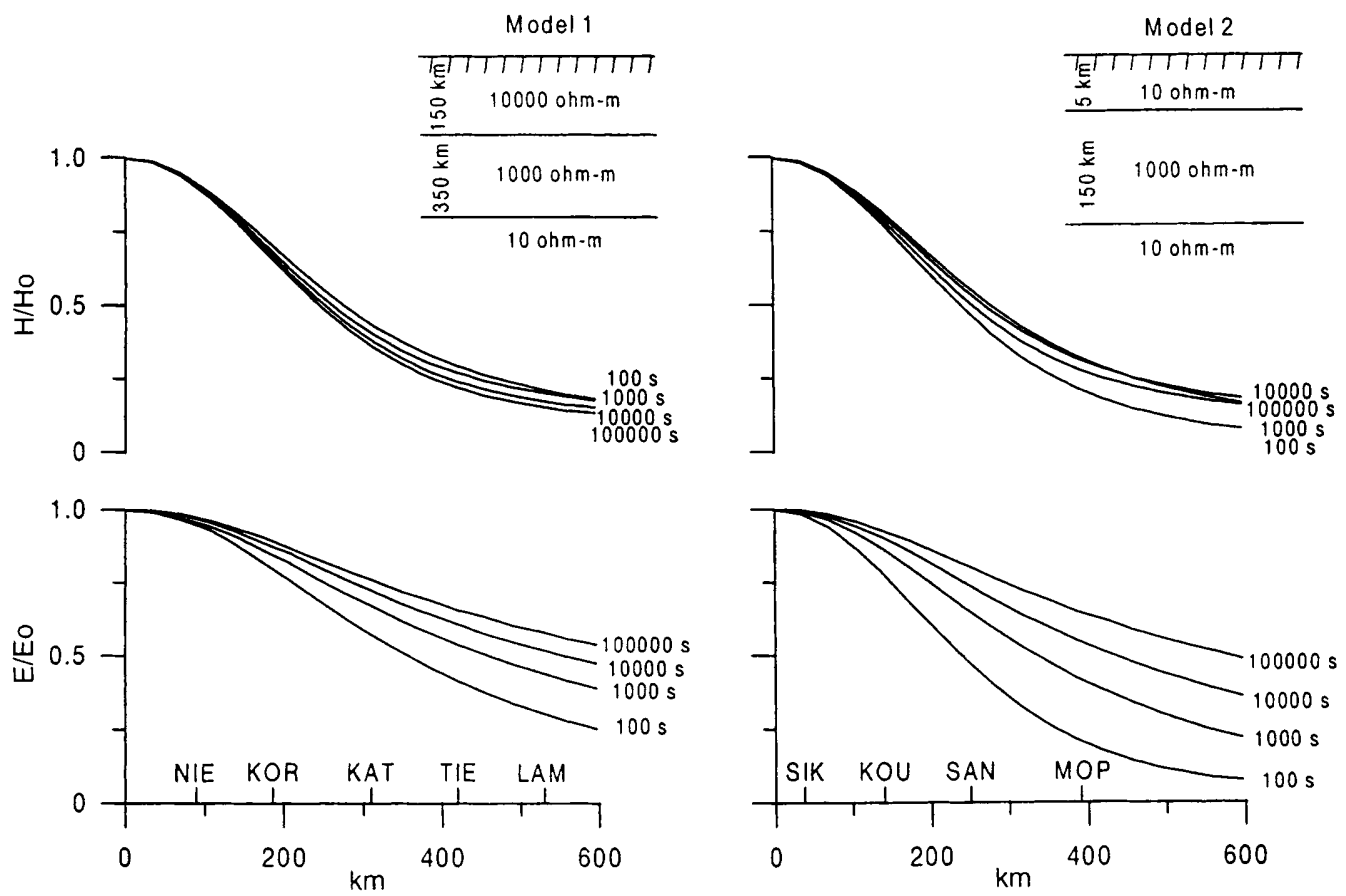

Fig. 8. Relative variations of $E_{y}$ and $H_{x}$ obtained for a gaussian electrojet and for two models corresponding to the mean stratified structure of the Earth below the northern (low resistivity sedimentary

basin; right panel) and southern (continental shield; left panel) parts of the electromagnetic IEEY profile (see text and Table 3 for a complete description of the two models) 
2. The source responsible for the observed electric field $\mathrm{S}_{\mathrm{R}}^{\mathrm{E}}$ variation, which is also likely to be an ionospheric source. This source seems to be located close to the dip equator, and to have a typical extent of few hundred kilometers with variations over distances significantly smaller than one hundred kilometers. To our knowledge, these sources have not yet been described. For the sake of clarity, we propose to denote $S_{\mathrm{R}}^{\mathrm{E}}$ as the diurnal variation and ionospheric sources associated to equatorial electrojet and counter electrojet and already studied by many authors, and $\mathrm{S}_{\mathrm{R}}^{* \mathrm{E}}$ as the ionospheric sources responsible for the observed electric diurnal variation and their associated electromagnetic signature.

\subsection{Inferences on the possibility of probing the Earth's conductivity}

4.3.1 Electromagnetic soundings with irregular variations. The analysis made in Sect. 3.3 of the irregular variations showed that the change observed in the intensity of the electric field variations from north to south of the Sikasso station marked a significant change in the conductive structure of the Earth. As already stated, geological observations show that this change corresponds to the limit between a sedimentary basin to the north and a continental shield to the south. At night, the Tikhonov-Cagniard hypothesis (plane wave $+1-\mathrm{D}$ underlying medium, see Sect. 3.1) holds, and classical magnetotelluric techniques allow one to probe the conductive structure of the Earth.

It is common in magnetotelluric studies to compute the apparent resistivity $\rho_{A}$, related to the impedance $Z=E_{y} / H_{x}$ through:

$\rho_{A}=\frac{1}{\omega \mu_{0}}\left|\frac{E_{y}}{H_{x}}\right|^{2}$

Since $Z$, and then $\rho_{A}$ depend only on the electrical structure of the crust and upper mantle when the Tikhonov-Cagniard hypothesis holds, different apparent resistivity curves would correspond to different 1-D resistivity profiles.

Using night-time variations of frequency in the range $5 \cdot 10^{-2}$ to $10^{-4} \mathrm{~Hz}$, Ritz (1983) and Ritz and Robineau (1986) probed the distribution of electric resistivity in West Africa by means of dense magnetotelluric sounding profiles. Their results demonstrated the absence of conductive layer within the Earth's crust in Niger. However, Ritz (1984) found a locally high conductivity anomaly in Mali. The Senegal basin has also been studied (Ritz and Vassal, 1986, 1987), allowing the determination of sediment thickness and resistivity to be made.

The most important feature of these results is actually the contrast in the observed resistive structure of the craton and the basin region. Various different models representing the structure underlying the basin and craton tectonic features have been proposed. The most salient features of these models are summarized as follows:
1. In the craton, a highly resistive near-surface material (5000-10 $000 \Omega-\mathrm{m}$ ) is encountered to a depth of about $150 \mathrm{~km}$, which overlies a less resistive layer (500-1000 $\Omega-\mathrm{m}$ ) with thickness of $250-400 \mathrm{~km}$;

2. In the basin zone, the models show a resistive layer $(1000 \Omega-\mathrm{m}$,$) underlaid by a thin (3-10 \mathrm{~km})$ conductive layer $(<50 \Omega-\mathrm{m})$.

3. In both cases, a more conductive layer with a resistivity of $10 \Omega-\mathrm{m}$ seems to exist, but its actual depth is not well constrained by the data which only provide evidence of the existence of a deep lateral discontinuity in the resistive structure. The depth of this conductive layer is generally estimated at about $150-250 \mathrm{~km}$ below the basin, and at about $500 \mathrm{~km}$ below the craton.

It should be noted that the dip equator in West Africa corresponds to the boundary between the craton and the basin. Since evidence of this deep discontinuity can be found from night-time data, it can be considered as a true feature of the electric structure of the crust and upper mantle in West Africa. On the contrary, estimating the depth of the deep conductive layer requires data from the low frequency range, which cannot be deduced from night-time recordings alone. Significant source effects due to the electrojet might consequently exist, thus casting doubt on the validity of the results obtained using the classical Cagniard-Tikhonov's MT hypothesis.

The actual structure of the craton and the basin zones may vary from place to place, and the observed resistivity structures may be $3-\mathrm{D}$. The two models considered in Sect. 4.1.2 are a possible simplified synthesis of the estimated average variation of resistivity as a function of depth. These models do not represent the actual situation at any place in particular.

Consider now the situation during daytime disturbed magnetic conditions, when the equatorial electrojet may give rise to a source effect in the magnetotelluric impedance. In order to discuss the source effect related to the equatorial electrojet, we computed apparent resistivities with the electric and magnetic field estimates made in Sect. 4.1.2. Figure 9 shows the variations of the apparent resistivities obtained, expressed as a function of frequency for the two models we considered, and for different distances $x$ to the center of the equatorial electrojet. For each model, the shape of the apparent resistivity curves is significantly dependent on $x$, and indicates the existence of a source effect related to the equatorial electrojet. The source effect exists over almost the whole frequency range we consider $\left(5 \cdot 10^{-5}\right.$ to $10^{-2} \mathrm{~Hz}$ ), these being the case of a highly resistive continental shield (Table 3, model 1) and for frequencies larger than about $2.5 \cdot 10^{-3} \mathrm{~Hz}$ in presence of a low resistivity sedimentary basin (Table 3 , model 2 ).

We also computed apparent resistivities corresponding to daytime (09:00 a.m. to 08:00 p.m. LT) and nighttime $(10: 00$ p.m. to 07:00 a.m. LT) data respectively. Apparent resistivity values were computed with the offdiagonal term $Z_{y x}$ of the impedance tensor estimates obtained using the robust method for magnetotelluric data processing proposed by Chave et al. (1987). Both 
night-time and daytime impedances are estimated with tens of samples from a period ranging from December 1992 to March 1993.

Figure 10 presents the daytime (continuous line) and night-time (dashed line) apparent resistivity curves observed at four stations: from south to north, Koutiala (KOU), Nielle (NIE), Katiola (KAT) and Korhogo (KOR) (see Fig. 1 and Table 1). The differences observed between daytime and night-time curves provide experimental evidence for a daytime source effect related to the equatorial electrojet for frequencies in the range $10^{-2}$ to $10^{-4} \mathrm{~Hz}$. Assume a gaussian distribution of daytime east-west ionospheric currents and compare the observed apparent resistivity curves to those computed for the two tabular models of Earth described in Table 3 in the plane wave approximation (accounting for the night-time situation) on the one hand, and with a gaussian ionospheric source (accounting for the daytime situation) on the other hand. For the sake of clarity the observed curves are hereafter denoted daytime and night-time curves, while the computed curves are denoted gaussian and plane wave curves.

Figure 10 shows that the source effect increased from the south to the north of the IEEY profile:

1. A fairly small source effect was observed at the Katiola (KAT) station, located in the continental shield domain about $300 \mathrm{~km}$ to the south of the center of the equatorial electrojet. The corresponding gaussian curve is number 2 on the left panel of Fig. 9. It is not significantly different from the plane wave curve (dotted curve on the same panel), which accounts for the small difference observed between the night-time and daytime curves. It is worth noting that the relative positions of the gaussian and plane wave curves are similar to that observed for the daytime and night-time curves;

2. The observed source effect was more significant at the Korhog (KOR) station, also located in the continental shield domain, but about $180 \mathrm{~km}$ to the south of the center of the equatorial electrojet. The corresponding gaussian curve (number 1 on the left panel of Fig. 9) is significantly different from the plane wave curve, and corresponds to lower apparent resistivities as the daytime curve is with respect to the night-time curve for this station;

3. The source effect increased in a northwards direction, as illustrated by the daytime and the night-time curves observed at the Nielle (NIE) station, located in continental shield domain almost below the equatorial electrojet. In this case again, the difference between the corresponding gaussian curve (number 0 on the left panel of Fig. 9) and the plane wave curve accounts quite well for the observed difference between the daytime and night-time curves;

4. A more important source effect was in fact observed to the north of the equatorial electrojet, as illustrated by the daytime and night-time curves observed at the

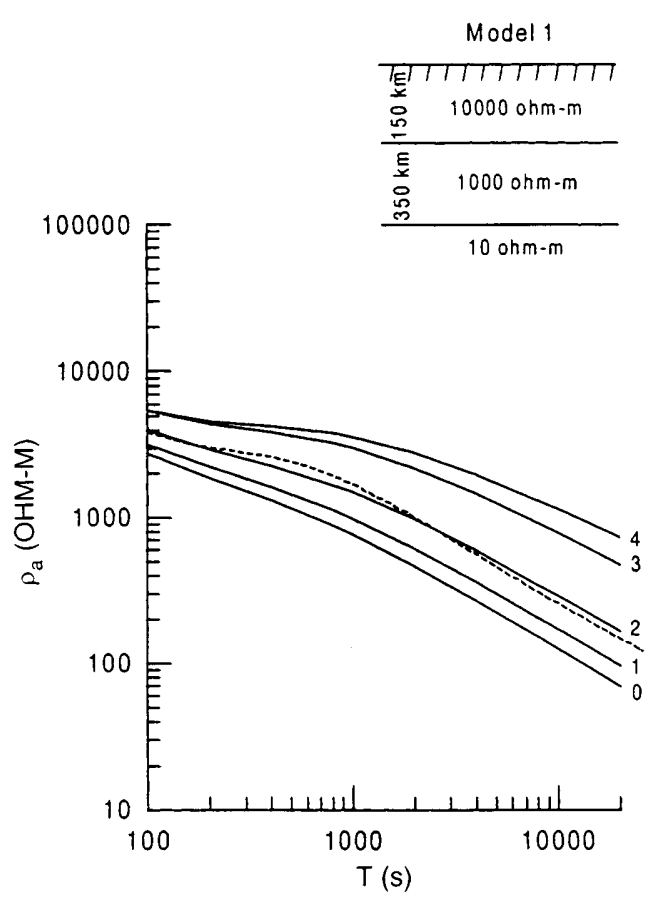

Fig. 9. Apparent resistivity curves for the same models of Earth as in Fig. 8. For each model, the continuous curves correspond to a gaussian distribution of ionospheric currents, and are denoted in the text as gaussian curves. They are computed at five observation points, and labelled from 0 to 4 according to the distance of the point to the center of the electrojet, the curve labelled $n$ corresponding to $a n$ times

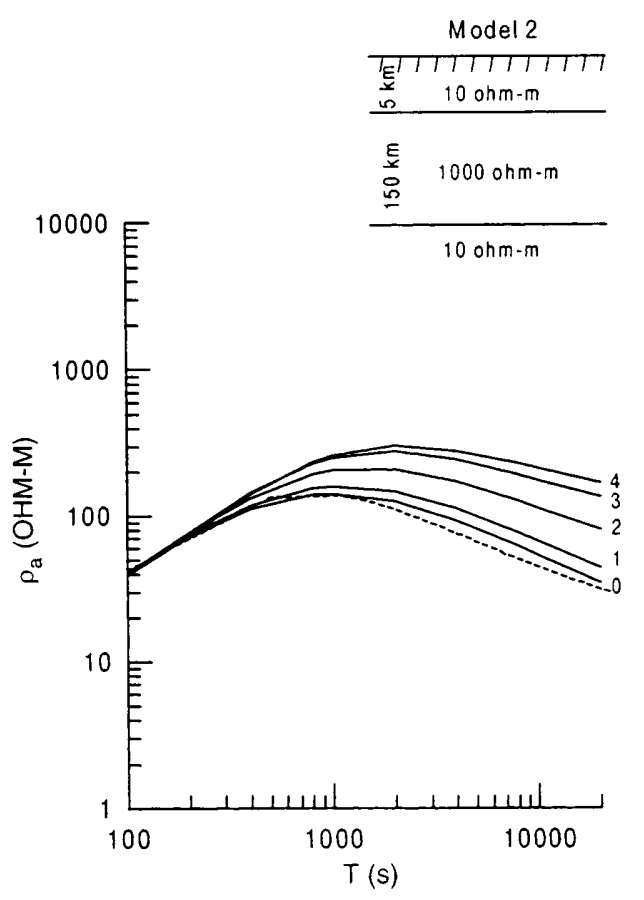

a distance $(a=140 \mathrm{~km}$ is the standard deviation of the Gaussian current distribution, see text for further explanations). The dotted curves correspond to Cagniard-Tikhonov apparent resistivities, and are denoted in the text as plane wave curves. For the sake of tradition and convenience, the apparent resistivities are plotted as a function of the period 
Koutiala (KOU) station. At this station, however, and in contrast to what was observed at the three other stations, the observed daytime apparent resistivities were larger than the night-time resistivities. The Koutiala station was located about $150 \mathrm{~km}$ to the north of the equatorial electrojet, over a low resistivity sedimentary basin. The comparison between the corresponding gaussian (number 2 one on the right panel of Fig. 9) and the plane wave (dotted line) curves accounts well for the observed difference between the daytime and night-time curves.

These results show that the induction by a gaussian eastwest electrojet in very simple models of the Earth provides an explanation for the observed daytime source effect. It is clear that studying the electric field structure of the crust and upper mantle below the IEEY electromagnetic profile would require more detailed investigations, in particular because of the presence of 3D structures resulting in significant static shifts at some stations (see e.g., Menvielle, 1988 and references therein for a description of the static shift).

The results presented in Fig. 9 and 10 also demonstrate that the source effect related to the equatorial electrojet depends on the width of the electrojet, the

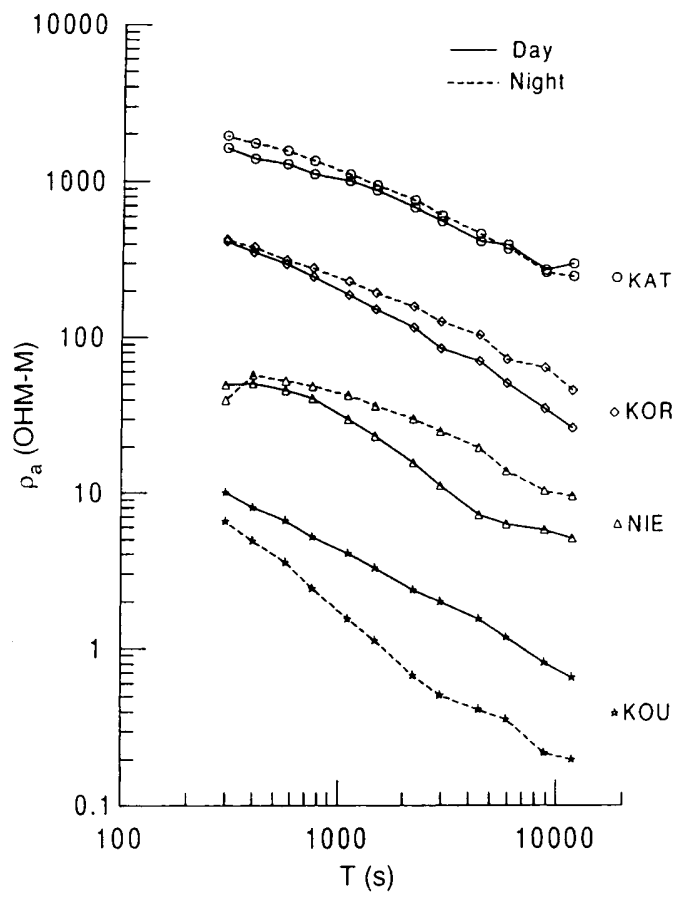

Fig. 10. Apparent resistivity estimated with daytime (09:00 a.m. to 08:00 p.m. LT; continuous line) and night-time (10:00 a.m. to 07:00 a.m. LT; dashed line) data from four stations distributed along the IEEY profile: from south to north, Koutiala $(K O U)$, Nielle $(N I E)$, Katiola $(K A T)$ and Korhogo $(K O R)$ (see Fig. 1 and Table 1). Apparent resistivity values are computed with the off-diagonal term $Z_{y x}$ of the impedance tensor estimates obtained using the robust method for magnetotelluric data processing proposed by Chave et al. (1987). Both night-time and daytime estimates are made with tens of samples from a period ranging from december 1992 to March 1993. For the sake of tradition and convenience, the apparent resistivities are plotted as a function of the period distance to its center, the frequency, and the local geology. This may easily explain the difference between our results and those obtained in Brazil by Padilha et al. (1997) for frequencies ranging from $5 \cdot 10^{-4}$ to about $2000 \mathrm{~Hz}$.

If not taken into account, such a source effect together with the corresponding deviation from the Tikhonov-Cagniard's apparent resistivity curves, would result in errors in the estimated variation of resistivity with depth. Since different apparent resistivity curves correspond to different resistivity profiles, interpreting the apparent resistivity curves presented Fig. 9 in terms of Tikhonov-Cagniard models would, for both models, result in a conductive structure dependent on $x$ which is not actually the case. Given the fact that the lower the frequency, the larger is the source effect, the error in the resistivity profile would be expected to increase with increasing depths. This example provides further confirmation that it is mandatory to take into account the geometry of the ionospheric currents associated with the equatorial electrojet when using daytime recordings to probe the conductive structure of the Earth at dip equator latitudes.

\subsubsection{Electromagnetic soundings with regular variations.} During quiet magnetic situations, our results demonstrated the existence of two different ionospheric sources; one of these (the $\mathrm{S}_{\mathrm{R}}^{\mathrm{E}}$ source) driving most of the magnetic diurnal variation, and the other (the $S_{R}^{* E}$ source) responsible for most of the electric field variation. Diurnal variations in electric and magnetic fields are therefore related to different ionospheric sources, such that interpreting the electric diurnal variation induced by the magnetic field variation is not relevant. Magnetotelluric probing of the upper mantle at dip equator latitudes with the electromagnetic diurnal variation is consequently impossible to achieve.

Furthermore, the existence of two different ionospheric sources implies that the magnetic diurnal variation actually has two components, corresponding to the magnetic signature of the $S_{R}^{E}$ and $S_{R}^{*}$ sources, respectively. Although the magnetic signature of the $S_{R}^{*}{ }_{R}$ source should exist, our results show that it was very small compared to that of the $\mathrm{S}_{\mathrm{R}}^{\mathrm{E}}$. However, we have no evidence of the relative intensity of the $S_{R}^{*}{ }_{R}{ }^{E}$ magnetic variation compared to that of the induced part of the $S_{R}^{E}$ variation, which has been shown to be in the order of a few percent of the observed magnetic diurnal variation (Fambitakoye and Mayaud, 1976a; Ducruix et al., 1977). Geomagnetic deep soundings rely upon the comparison between observed magnetic variations and their estimated induced part for a known geometry of the external source. The existence of a magnetic variation related to another source with different time and space characteristics and in which the intensity may be comparable to, if not greater than, the induced part of the $S_{R}^{E}$ magnetic variation, may therefore result in inconsistent interpretations, thus casting doubt on the results of deep geomagnetic soundings based upon the diurnal variation in equatorial electrojet regions. 


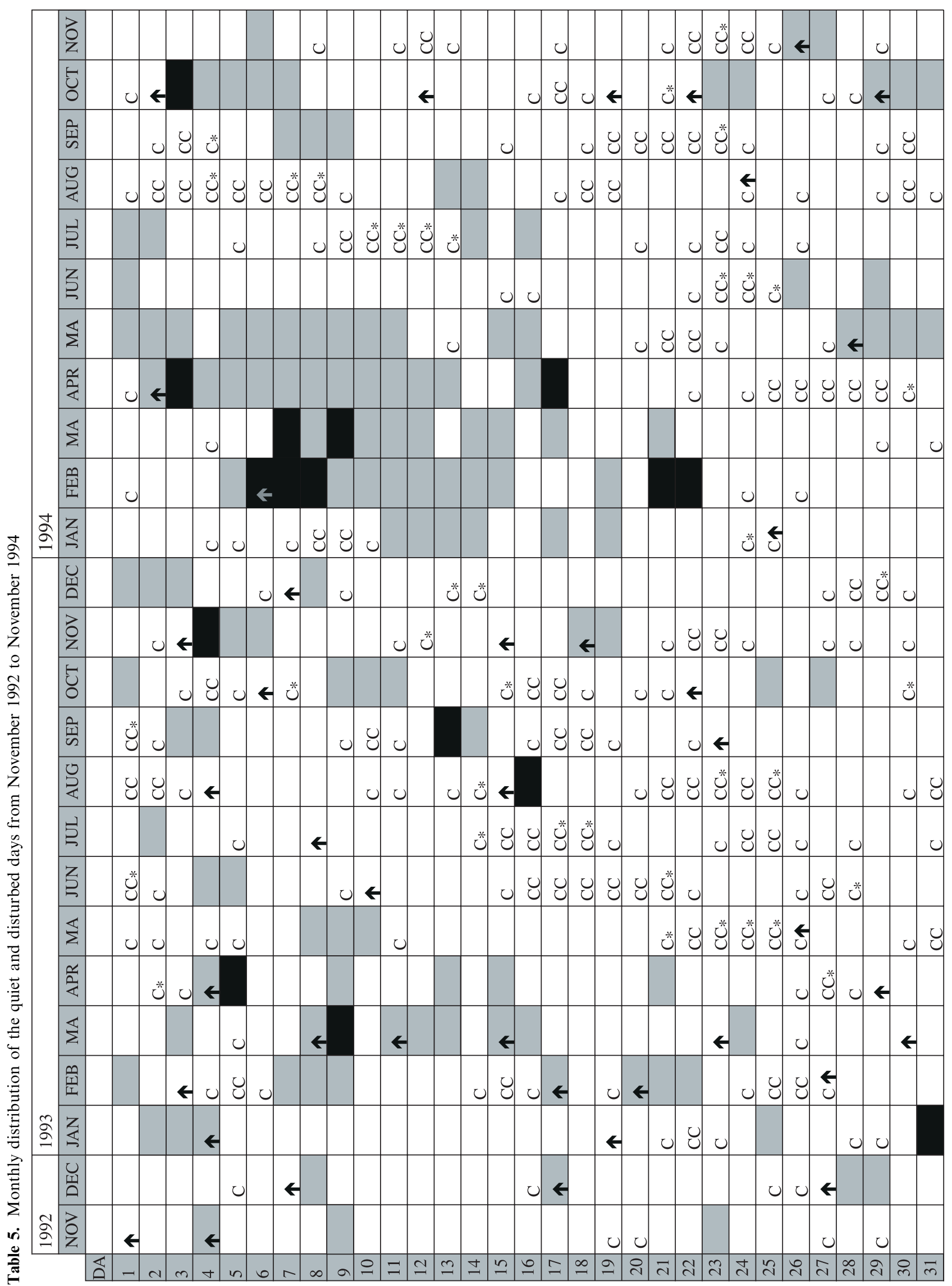




\section{Conclusion}

The electromagnetic experiment carried out at African longitudes during the IEEY has provided the first set of continuous recordings of both electric and magnetic variations covering a network of 10 stations over a period of four months. The major result stemming from this experiment was that diurnal variations in the electric and magnetic fields do not show the same day-to-day variability in the equatorial regions.

An analysis of the regular variation in the electric field demonstrated the existence of a diurnal variation in the electric field. The time and space characteristics of the observed electric field diurnal variation showed that it was not induced by the magnetic $S_{R}^{E}$ variation associated with the equatorial electrojet, and already described by many authors (see e.g. Fambitakoye and Mayaud, 1976a; Doumouya et al., 1997). It therefore corresponded to another ionospheric source in existence at dip equatorial latitudes. We propose to call $\mathrm{S}_{\mathrm{R}}^{*} \mathrm{E}$ this new source. The magnetic signature of the $\mathrm{S}_{\mathrm{R}}^{* \mathrm{E}}$ is small compared to that of the $S_{R}^{\mathrm{E}}$, and was not detected using magnetic recordings only.

The dominant parts of both the electric and magnetic field diurnal variations are not related to the same ionospheric sources. Consequently, these variations cannot be used to perform electromagnetic soundings.

An analysis of the irregular variations confirmed the existence of a significant increase in the intensity of irregular electric variations during the daytime, which corresponded to the daytime enhancement of irregular magnetic variations, and thus to the daytime enhancement of ionospheric conductivity related to the equatorial electrojet. The Tikhonov-Cagniard classical MT hypothesis no longer held for daytime analysis, with numerical simulations showing that a significant source effect was likely to exist for frequencies down to $10^{-2} \mathrm{~Hz}$, or even less in the case of very resistive cratonic shield. The classical Tikhonov-Cagniard MT approach is therefore only valid for night-time data, providing a lower boundary to the range of frequencies that can be used for MT soundings. The range of depth which can be probed is accordingly limited.

Acknowledgements. This study was supported by a grant from ORSTOM. The French participation in the IEEY experiment benefited from the financial support of the French Ministère d'Aide et de Coopération through the Opération CAMPUS 'Année Internationale de l'Electrojet Equatorial' between the Universities of Paris-Sud and Abidjan.

Topical Editor D. Alcaydé thanks F. E. M. Lilley and C. Sucksdorff for their help in evaluating this paper.

\section{Appendix}

\section{Classification of quiet and disturbed days}

The list of selected quiet and disturbed days during IEEY campaign is given month by month in Table 5 . The selection of quiet days is inspired by Mayaud's classification (Mayaud, 1980) and adapted to obtain enough significant number of days.

The classification of quiet days is deduced from am indices and made according to the following. The selection of the quiet 24-h intervals is made firstly on the basis of the mean value of am $(A m)$. Then, each individual three-hour am value of the day is represented by a weight $p$, namely:

$\begin{array}{llllll}\mathrm{p} & 0 & 1 & 2 & 4 & 6 \\ \mathrm{am} & \leq 17 & 17<\mathrm{am} \leq 21 & 21<\mathrm{am} \leq 28 & 28<\mathrm{am} \leq 32 & >32\end{array}$

A day with a mean value of $a m \leq 13 \mathrm{nT}$ and for which $\sum p \leq 4$ is a really quiet C-day. In the same way, if the mean value of $a m \leq 6 \mathrm{nT}$ and each individual am value $\leq 10 \mathrm{nT}$ the day is noted as a very quiet $\mathrm{C} *$-day. Marks $\mathrm{CC}$ and $\mathrm{CC} *$-indicate the really and very quiet $48 \mathrm{~h}$ intervals. One has to note that in these CC-days every local day ( $0 \mathrm{~h}$ to $24 \mathrm{~h}$ in local time) is quiet at any longitude.

The light gray shaded days indicate disturbed days with mean value of $a m>40 \mathrm{nT}$, and those dark gray shaded have mean value of am $>80 \mathrm{nT}$. The storm sudden commencements (ssc), noted by vertical arrows $(\uparrow)$, are derived from provisional list collected and prepared at the observatorio del Ebro.

During the 760 days of IEEY campaign, we have selected $29 \%$ of quiet days including $11 \%$ of CC-days and $5 \%$ of $*$-days, and $19 \%$ of disturbed days.

\section{References}

Akasofu, S. I., Physics of magnetospheric substorms, D. Reidel, Norwood, Mass, 1977.

Bessoles, B., Géologie de l'Afrique. 1. Le craton Ouest Africain, Mem. Bur. Rech. Géol. Min., 88, 108-115, 1977.

Bitterly, J., J. M. Cantin, J. Burdin, R. Schlich, J. Folques, and D. Gilbert, Digital recording of variations in the Earth's magnetic field in French observatories: description of equipment and results for the period 1978-1986, in Proceedings of the international workshop on magnetic observatory instruments, Coles, $\mathrm{R}$. L. Ed, 59-66, Geomagnetic series 32, Geological Survey of Canada, Ottawa, 1988.

Cagniard, L., Principe de la méthode magnéto-tellurique, nouvelle méthode de prospection géophysique, Ann. Geophysicae, 9, 95$125,1953$.

Chapman, S., Equatorial electrojet as detected from the abnormal electric current distribution above Huancayo, Peru, and elsewhere, Arch. f. Meteorol. Geophys. Bioklimatol., 4, 368-390, 1951.

Chave, A. D., D. J. Thomson, and M. E. Ander, On the robust estimation of power spectra, coherencies, and transfer functions, J. Geophys. Res., 92, 633-648, 1987.

Clerc, G., Z-mètre à vannes de flux: étude du prototype de capteur, CRG/INSU/05/92, Centre de Recherches Géophysique, Garchy, France, 1992.

Counil, J. L., J. L. Le Mouel, and M. Menvielle, A study of the diurnal variation of the electromagnetic field in Northern France using ancient recordings, Geophys. J. R. Astr. Soc., 78, 831-846, 1984.

Doumouya, V., J. Vassal, Y. Cohen, O. Fambitakoye, and M. Menvielle, Equatorial electrojet at African longitudes: first results from magnetic measurements, Ann. Geophysicae, this issue, 1997. 
Ducruix, J., V. Courtillot, and J. L. Le Mouël, Induction effects associated with the equatorial electrojet, J. Geophys. Res., 82, 335-351, 1977.

Duhau, S., and A. Favetto, The conductosphere depth at equatorial latitudes as determined from geomagnetic daily variation, PAGEOPH, 134, 559-574, 1990.

Fairfield, D. H., Recent advances in magnetospheric substorm research, J. Atmos. Terr. Phys., 52, 1155-1167, 1990.

Fambitakoye, O., Etude des effets magnétiques de l'Electrojet équatorial, Thèse d'Etat. ORSTOM, 1976.

Fambitakoye, O., and P. N. Mayaud, Remarques sur les effets externes et internes à Huancayo, Ann. Geophysicae, 29, 168-169, 1973.

Fambitakoye, O., and P. N. Mayaud, The Equatorial electrojet and regular daily variation $S_{R}-I$. A determination of the equatorial electrojet parameters, J. Atmos. Terr. Phys., 38, 1-17, 1976a.

Fambitakoye, O., and P. N. Mayaud, The Equatorial electrojet and regular daily variation $\mathrm{S}_{\mathrm{R}}-$ II. The centre of the equatorial electrojet, J. Atmos. Terr. Phys., 38, 19-26, 1976b.

Fambitakoye, O., and P. N. Mayaud, The Equatorial electrojet and regular daily variation $S_{\mathrm{R}}-\mathrm{IV}$. Special features in particular days, J. Atmos. Terr. Phys., 38, 123-134, 1976c.

Fambitakoye, O., P. N. Mayaud, and A. D. Richmond, The Equatorial electrojet and regular daily variation $\mathrm{S}_{\mathrm{R}}-\mathrm{III}$. Comparison of observations with a physical model, J. Atmos. Terr. Phys., 38, 113-121, 1976.

Fambitakoye, O., R. G. Rastogi, J. Tabbagh, and P. Vila, Counter electrojet and Esq disappearance, J. Atmos. Terr. Phys., 35, 1119-1126, 1973

Forbes, J. M., The equatorial electrojet, Rev. Geophys. Space Phys., 19, 469-504, 1981.

Gish, O. H., and W. J. Rooney, Results of Earth current observations at Huancayo Magnetic Observatory, Terr. Mag. Atmos. Elect., 35, 213-224, 1930.

Gouin, P., and P. N. Mayaud, A propos de l'existence possible d'un contre-électrojet aux latitudes équatoriales, Ann. Geophysicae 23, 41-47, 1967.

Hermance, J. F., and W. R. Peltier, Magnetotelluric fields of a line current, J. Geophys. Res., 75, 3351-3356, 1970.

Hutton, R., The solar and lunar daily variations of Earth currents near the magnetic equator, J. Atmos. Terr. Phys., 24, 673-680, 1962.

Hutton, R., Some problems of electromagnetic induction in the Equatorial electrojet region - 1 magneto-telluric relations, Geophys. J. R. Astr. Soc., 28, 267-284, 1972.

Hutton, R., and R. W. H. Wright, Diurnal variation of Earth currents at the equator, J. Atmos. Terr. Phys., 20, 100-109, 1961.

Kamide, Y., Electrodynamic processes in the Earth's ionosphere and magnetosphere, Kyoto Sangyo University Press, Kyoto, Japan, 1988.

Langel, R. A. M., M. Purucker, and M. Rajaram, The equatorial electrojet and associated currents as seen in MAGSAT data, $J$. Atmos. Terr. Phys., 55, 1233-1269, 1993.

Mayaud, P. N., Analyse morphologique de la variabilité jour-àjour de la variation solaire régulière $S_{R}$ du champ magnétique terrestre. 1. Le système de courants $\mathrm{C}_{\mathrm{P}}$ (régions polaires et subpolaires), Ann. Geophysicae., 21, 369-401, 1965a.

Mayaud, P. N., Analyse morphologique de la variabilité jour-àjour de la variation solaire régulière $S_{R}$ du champ magnétique terrestre. 2. Le système de courants $\mathrm{C}_{\mathrm{m}}$ (régions non polaires), Ann. Geophysicae, 21, 514-544, 1965 b.

\section{Note added in Proof:}

The existence of the local ionospheric source responsible for the observed electric diurnal variations, named $S_{R}{ }^{E}$ in section 4.2 , seem have been recently deduced from the study of the return current of the equatorial electrojet using the POGO data. (cf. C.A. Onwumechili, Spatial and temporal distributions of ionospheric currents in subsolar elevations, J. Atmos. Solar-Terr. Phys., 59, 1891-1899, 1997)
Mayaud, P. N., Derivation, meaning and use of geomagnetic indices, Geophys. Monograph 22, American Geophysical Union, Washington, 1980.

Mazaudier, C., and M. Blanc, Electric currents above Saint Santin, 2. Model, J. Geophys. Res., 87, 2465-2480, 1982.

Menvielle, M., Effects of crustal conductivity heterogeneities on the electromagnetic field, Surv. Geophys., 9, 319-348, 1988.

Menvielle, M., and A. Berthelier, The K-derived planetary indices: description and availability, Rev. Geophys. Space Phys., 29, 415-432, 1991.

Menvielle, M., J. C. Rossignol, and P. Tarits, The coast effect in terms of deviated electric currents: a numerical study, Phys. Earth Planet. Inter., 28, 118-128, 1982.

Mosnier, J., and P. Yvetot, Nouveau type de variomètre à aimant asservi en direction, Ann. Geophysicae, 28, 219-224, 1972.

Mosnier, J., and P. Yvetot, Nouveau type de variomètres horizontaux à asservissement de champ et capteur capacitif, Ann. Geophysicae, 33, 391-396, 1977.

Onwumechilli, A., and P. C. Ozoemena, Latitudinal extent of the Equatorial electrojet, J. Geomag. Geoelectr., 37, 193-204, 1985.

Padilha, A. L., I. Vitorello and L. Rijo, Effects of the Equatorial electrojet on magnetotelluric surveys: field results from northwest Brazil, Geophys. Res. Lett., 24, 89-92, 1997.

Parkinson, W. D., Direction of rapid geomagnetic fluctuations, Geophys. J. R. Astr. Soc., 2, 1-13, 1959.

Peltier, W. R., and J. F. Hermance, Magnetotelluric fields of a Gaussian electrojet, Can. J. Earth Sci., 8, 338-346, 1971.

Petiau, G., and A. Dupis, Noise, temperature coefficient, and long term stability of electrodes for telluric observations, Geophys. Prospect., 28, 792-804, 1980.

Ponsard, J. F., La marge du craton Ouest Africain du Sénégal à la Sierra Leone: interprétation géophysique de la chaîne panafricaine et des bassins du Protérozo à l'actuel, Université d'AixMarseille III, 1984.

Richmond, A. D., Equatorial electrojet. I. Development of a model including winds and instabilities, J. Atmos. Terr. Phys., 35, 1083-1103, 1973.

Ritz, M., The distribution of electric conductivity on the eastern border of the West African craton (Republic of Niger), Geophys. J. R. Astr. Soc., 73, 475-488, 1983.

Ritz, M., A high conductivity anomaly on the West African craton (Mali), J. Geophys., 55, 182-184, 1984.

Ritz, M., and B. Robineau, Crustal and upper mantle electric conductivity structures in West Africa: geodynamic implications, Tectonophysics, 124, 115-132, 1986.

Ritz, M., and J. Vassal, The geoelectrical structure of the northern part of the Senegal basin from joint interpretation of magnetotelluric and geomagnetic data, J. Geophys. Res., 91, 1044310456, 1986

Ritz, M., and J. Vassal, A magnetotelluric traverse across the Mauritanides orogenic belt (West Africa), Geophys. J. R. Astr. Soc., 91, 43-56, 1987.

Schmucker, U., An introduction to induction anomalies, $J$. Geomag. Geoelectr., 22, 9-33, 1970.

Srivastava, S. P., Method of interpretation of magnetotelluric data when the source field is considered, J. Geophys. Res., 70, 945954, 1965.

Tikhonov, A. N., On investigation of electrical characteristics of deep strata of Earth's crust, Dokl. Akad. Nauk SSS, 73, 295297,1950 . 